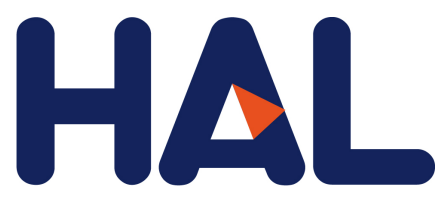

archives-ouvertes

\title{
Climate affects neighbour-induced changes in leaf chemical defences and tree diversity-herbivory relationships
}

Charlotte Poeydebat, Hervé Jactel, Xoaquín Moreira, Julia Koricheva, Nadia Barsoum, Jürgen Bauhus, Nico Eisenhauer, Olga Ferlian, Marta Francisco, Felix Gottschall, et al.

\section{To cite this version:}

Charlotte Poeydebat, Hervé Jactel, Xoaquín Moreira, Julia Koricheva, Nadia Barsoum, et al.. Climate affects neighbour-induced changes in leaf chemical defences and tree diversity-herbivory relationships. Functional Ecology, Wiley, In press, 10.1111/1365-2435.13700 . hal-02986320

\section{HAL Id: hal-02986320 \\ https: / hal.archives-ouvertes.fr/hal-02986320}

Submitted on 2 Nov 2020

HAL is a multi-disciplinary open access archive for the deposit and dissemination of scientific research documents, whether they are published or not. The documents may come from teaching and research institutions in France or abroad, or from public or private research centers.
L'archive ouverte pluridisciplinaire HAL, est destinée au dépôt et à la diffusion de documents scientifiques de niveau recherche, publiés ou non, émanant des établissements d'enseignement et de recherche français ou étrangers, des laboratoires publics ou privés. 


\section{Climate affects neighbour-induced changes in leaf chemical defences and tree}

\section{2 diversity-herbivory relationships}

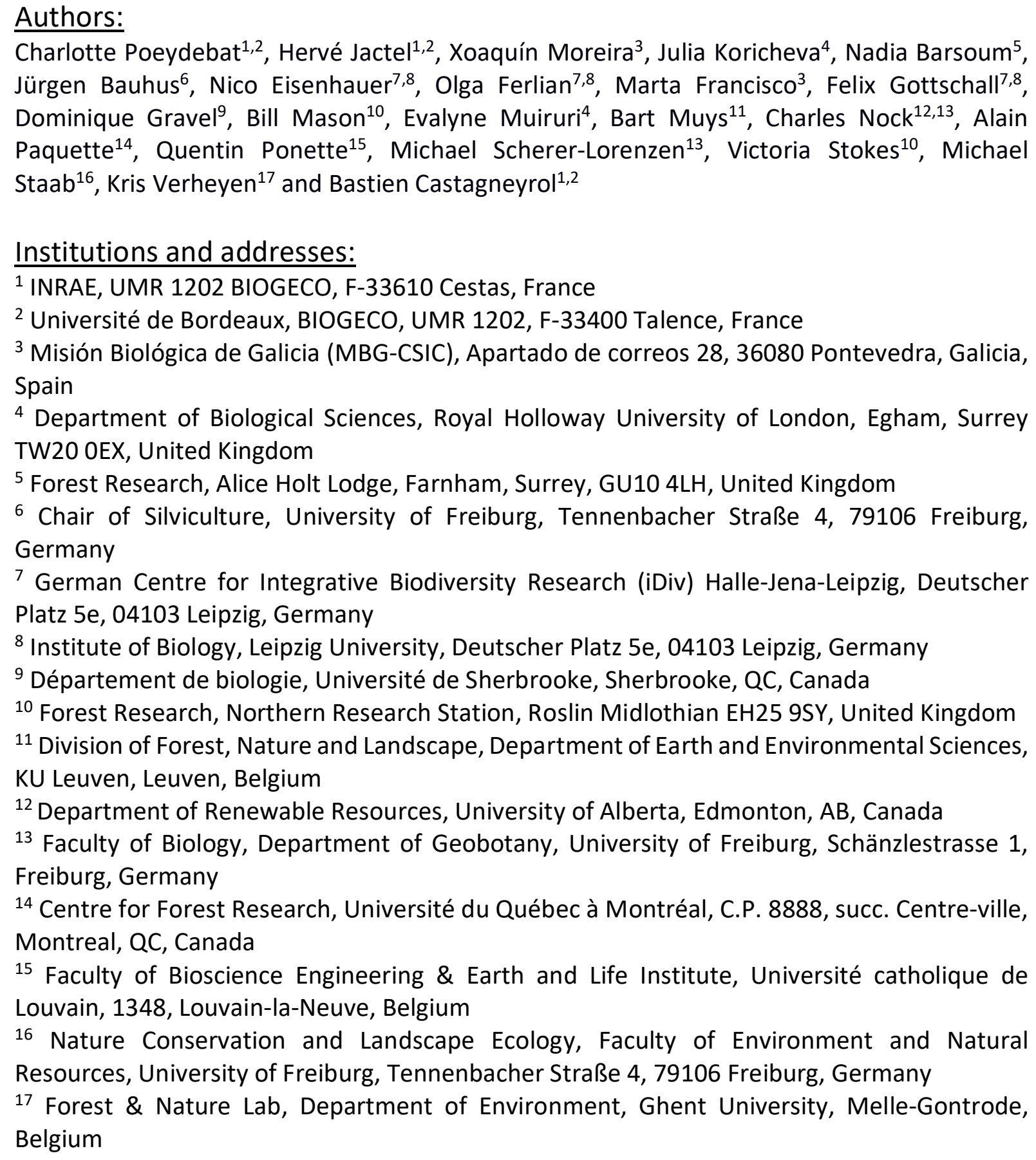
Jürgen Bauhus ${ }^{6}$, Nico Eisenhauer ${ }^{7,8}$, Olga Ferlian ${ }^{7,8}$, Marta Francisco ${ }^{3}$, Felix Gottschall7,8, Dominique Gravel $^{9}$, Bill Mason ${ }^{10}$, Evalyne Muiruri ${ }^{4}$, Bart Muys ${ }^{11}$, Charles Nock ${ }^{12,13}$, Alain Paquette $^{14}$, Quentin Ponette ${ }^{15}$, Michael Scherer-Lorenzen ${ }^{13}$, Victoria Stokes ${ }^{10}$, Michael Staab $^{16}$, Kris Verheyen ${ }^{17}$ and Bastien Castagneyrol ${ }^{1,2}$

Institutions and addresses:

${ }_{1}^{1}$ INRAE, UMR 1202 BIOGECO, F-33610 Cestas, France

2 Université de Bordeaux, BIOGECO, UMR 1202, F-33400 Talence, France

${ }^{3}$ Misión Biológica de Galicia (MBG-CSIC), Apartado de correos 28, 36080 Pontevedra, Galicia, Spain

${ }^{4}$ Department of Biological Sciences, Royal Holloway University of London, Egham, Surrey TW20 0EX, United Kingdom

${ }^{5}$ Forest Research, Alice Holt Lodge, Farnham, Surrey, GU10 4LH, United Kingdom

${ }^{6}$ Chair of Silviculture, University of Freiburg, Tennenbacher Straße 4, 79106 Freiburg, Germany

7 German Centre for Integrative Biodiversity Research (iDiv) Halle-Jena-Leipzig, Deutscher Platz 5e, 04103 Leipzig, Germany

${ }^{8}$ Institute of Biology, Leipzig University, Deutscher Platz 5e, 04103 Leipzig, Germany

${ }^{9}$ Département de biologie, Université de Sherbrooke, Sherbrooke, QC, Canada

${ }^{10}$ Forest Research, Northern Research Station, Roslin Midlothian EH25 9SY, United Kingdom

${ }^{11}$ Division of Forest, Nature and Landscape, Department of Earth and Environmental Sciences, KU Leuven, Leuven, Belgium

${ }^{12}$ Department of Renewable Resources, University of Alberta, Edmonton, AB, Canada

${ }^{13}$ Faculty of Biology, Department of Geobotany, University of Freiburg, Schänzlestrasse 1, Freiburg, Germany

${ }^{14}$ Centre for Forest Research, Université du Québec à Montréal, C.P. 8888, succ. Centre-ville, Montreal, QC, Canada

${ }^{15}$ Faculty of Bioscience Engineering \& Earth and Life Institute, Université catholique de Louvain, 1348, Louvain-la-Neuve, Belgium

16 Nature Conservation and Landscape Ecology, Faculty of Environment and Natural Resources, University of Freiburg, Tennenbacher Straße 4, 79106 Freiburg, Germany

17 Forest \& Nature Lab, Department of Environment, Ghent University, Melle-Gontrode, Belgium

Author for correspondence:

Charlotte Poeydebat, charlotte.poeydebat@zaclys.net 


\section{Abstract}

1. Associational resistance theory predicts that insect herbivory decreases with increasing tree diversity in forest ecosystems. However, the generality of this effect and its underlying mechanisms are still debated, particularly since evidence has accumulated that climate may influence the direction and strength of the relationship between diversity and herbivory.

2. We quantified insect leaf herbivory and leaf chemical defences (phenolic compounds) of silver birch (Betula pendula) in pure and mixed plots with different tree species composition across twelve tree diversity experiments in different climates. We investigated whether the effects of neighbouring tree species diversity on insect herbivory in birch, i.e. associational effects, were dependent on the climatic context, and whether neighbourinduced changes in birch chemical defences were involved in associational resistance to insect herbivory.

3. We showed that herbivory on birch decreased with tree species richness (i.e. associational resistance) in colder environments but that this relationship faded as mean annual temperature increased.

4. Birch leaf chemical defences increased with tree species richness but decreased with the phylogenetic distinctiveness of birch from its neighbours, particularly in warmer and more humid environments.

5. Herbivory was negatively correlated with leaf chemical defences, particularly when birch was associated with closely related species. The interactive effect of tree diversity and climate on herbivory was partially mediated by changes in leaf chemical defences.

6. Our findings demonstrate the complexity and context dependency of patterns and mechanisms underlying associational resistance to insect herbivory in mixed forests.

\section{Keywords}

Associational effects, Betula pendula, evolutionary distinctiveness, leaf phenolics, mixed forests, phylogenetic distinctiveness, plant-insect interactions, TreeDivNet 


\section{Introduction}

The influence of plant species diversity on plant-herbivore interactions is an old but still topical question for ecologists (Castagneyrol, Kozlov, Poeydebat, Toïgo, \& Jactel, 2019; Haddad et al., 2009; Root, 1973; Russell, 1989; Siemann, Tilman, Haarstad, \& Ritchie, 1998). Ecological studies have demonstrated that increased plant species diversity generally leads to lower amount of damage caused by insect herbivores including in forests (Castagneyrol, Jactel, Vacher, Brockerhoff \& Koricheva, 2014; Iverson et al., 2014; Jactel \& Brockerhoff, 2007; Jactel, Moreira, \& Castagneyrol, in press; Letourneau et al., 2011), a phenomenon known as associational resistance (Barbosa et al., 2009). But several other studies have also reported no change (Cardinale et al., 2011; Haase et al., 2015) or even increased insect herbivory when mixing tree species, i.e. associational susceptibility (Castagneyrol, Jactel, \& Moreira, 2018; Loranger et al., 2014; Schuldt et al., 2010). These inconsistent findings demonstrate the need for improved understanding of ecological processes underlying tree diversity effects on insect herbivory in forests.

Plant diversity can reduce insect herbivory through host density-dependent or host traitdependent processes. First, several studies established that plant diversity not only dilutes the amount of resources available to a given herbivore (the resource concentration hypothesis, Hambäck, Inouye, Andersson, \& Underwood, 2014; Root, 1973), but also disrupt host-finding processes through reduced host chemical and visual apparency (Barbosa et al., 2009; Castagneyrol, Giffard, Péré, \& Jactel, 2013; Feeny, 1976; Jactel, Birgersson, Andersson, \& Schlyter, 2011; Zhang \& Schlyter, 2004). Second, plant diversity effects on insect herbivory can be indirectly driven by changes in plant chemical defences (i.e. indirect trait-mediated effects). Several reviews have shown that tree diversity can promote plant productivity (Zhang, Chen, \& Reich, 2012; Liang et al., 2016; Jactel et al., 2018), which in turn could result in reduced production of leaf chemical defences because of a trade-off between growth and defences (Coley, Bryant, \& Chapin, 1985; Herms \& Mattson, 1992; Endara \& Coley, 2011). Consistently, increased tree diversity was found to be associated with lower concentrations of leaf chemical defences, including polyphenols, tannins, glycosids and alkaloids (Castagneyrol et al., 2018; Muiruri et al., 2019; Rosado-Sánchez, Parra-Tabla, Betancur-Ancona, Moreira, \& AbdalaRoberts, 2018; Walter et al., 2012; but see Moreira, Abdala-Roberts, Parra-Tabla, \& Mooney, 2014). 
Assuming that tree species traits involved in interactions with herbivores or in resource acquisition are phylogenetically conserved, greater tree phylogenetic diversity should amplify trait dissimilarity between species (Srivastava, Cadotte, MacDonald, Marushia, \& Mirotchnick, 2012) and hence, the magnitude of associational resistance mechanisms including the effect of tree diversity on defences. In particular, greater plant functional diversity is expected to i) extend resource concentration effects to herbivore species with wider diet breadth (Castagneyrol et al., 2014), ii) foster host-finding disruption due to the greater complexity of the visual and chemical environments (the semiochemicals diversity hypothesis, Zhang \& Schlyter, 2004), and iii) increase resource use complementarity between plant species resulting in even higher growth and lower defence levels. Consistently, the degree of phylogenetic or functional dissimilarity between focal plant species and their heterospecific neighbours was found to affect associational effects on herbivory, with greater impacts than plant species richness per se in most cases (Castagneyrol et al., 2014; Dinnage, 2013; Jactel \& Brockerhoff, 2007; Ness, Rollinson, \& Whitney, 2011; Schuldt et al., 2014; Yguel et al., 2011).

The effects of climate on herbivore activity, abundance and diversity, as well as on plant growth and the production of plant anti-herbivore defences, including leaf phenolics, are well documented (Rodríguez-Castañeda, 2013; Jactel et al., 2019a; Kozlov, Lanta, Zverev, \& Zvereva, 2015; Moreira et al., 2018a). It has been shown that increased temperature may result in higher developmental rate and lower body mass of herbivorous insects (Pineau et al., 2017), as well as in higher rate of consumption by herbivores due to higher metabolic losses (Bauerfriend \& Fischer, 2013). Most studies to date have reported an increase of herbivore diversity and damage towards lower latitudes and elevations, which is generally interpreted as a positive effect of temperature and precipitation on herbivory (Kozlov et al., 2015; Moreira, Abdala-Roberts, Parra-Tabla, \& Mooney, 2015; Wang et al., 2016; but see Moles, Bonser, Poore, Wallis, \& Foley, 2011; Anstett, Chen, \& Johnson, 2016; Loughnan \& Williams, 2018). Besides, there is growing evidence that climate alters the chemistry of plants including trees and, hence, their nutritional quality for herbivores. For example, leaf nutritional quality may be reduced under drought conditions due to reduced leaf water and nitrogen contents, as well as increased leaf content in defensive phenolic compounds including flavonoids and tannins (Jactel et al., 2012; Moreira et al., 2018a; Mundim \& Pringle, 2018 but see Gutbrodt, Dorn, \& Mody, 2012; Walter et al., 2012). Plant nutritional quality is also expected to vary with 
temperature, with studies reporting a decrease of tree leaf phenolic content with increasing temperature (Kuokkanen, Julkunen-Tiitto, Keinänen, Niemelä, \& Tahvanainen, 2001; Moreira et al., 2018a; Veteli, Kuokkanen, Julkunen-Tiitto, Roininen, \& Tahvanainen, 2002).

The climate-dependency of associational effects has lately emerged as plausible explanation for the observed variability in diversity-herbivory relationships. A recent study suggested that the effects of tree species diversity on ecosystem functioning, including tree-insect interactions, might be modulated by climatic conditions (Ratcliffe et al., 2017). Furthermore, previous latitudinal and altitudinal studies have demonstrated that the strength and even the direction of plant-herbivore interactions can change with climate (Abdala-Roberts, Moreira, Rasmann, Parra-Tabla, \& Mooney, 2016; Rodríguez-Castañeda, 2013; Roslin et al., 2017; Schemske, Mittlebach, Cornell, Sobel, \& Roy, 2009). To date, climatic factors have been largely overlooked in studies on relationships between plant diversity and insect herbivory both at local and large scales (but see Castagneyrol et al., 2018; Jactel, Koricheva, \& Castagneyrol, 2019a; Jactel, Poeydebat, van Halder, \& Castagneyrol, 2019b; Kambach, Kühn, Castagneyrol, \& Bruelheidee, 2016; Walter et al., 2012).

Using a unique network of tree diversity experiments ranging from temperate to boreal biomes (TreeDivNet; Paquette et al., 2018), we quantified insect leaf herbivory and leaf chemical defences (phenolic compounds) in silver birch (Betula pendula) in plots with different tree species composition across twelve locations with different climates. First, we addressed the effects of tree species diversity on insect herbivory and leaf chemical defences in silver birch, asking which of tree species richness, birch phylogenetic distinctiveness or their combination best explained both response variables. We hypothesized that tree diversity was associated with lower herbivory (associational resistance) and lower chemical defence levels (due to higher complementarity and growth-defence trade-off), and that these effects were stronger when considering phylogenetic distinctiveness of the focal species instead of species richness, because phylogenetic diversity accounts for niche differentiation. Second, we tested whether diversity-herbivory and diversity-defences relationships depended on climate. Since there is no consensus in the literature to date, we had no particular directional hypothesis regarding the influence of climate. Finally, we tested whether climate and diversity effects on insect herbivory were mediated by changes in leaf chemical defences. Our study is one of the first to investigate defence-mediated associational effects on insect herbivory in relation with 
the climatic context. We aimed at building toward a more comprehensive understanding of the interactive effects of tree species diversity and climate on forest resistance to insect pests.

\section{Material and Methods}

\section{Natural history}

The silver birch (Betula pendula Roth, Betulaceae) is a deciduous tree native to most of Europe (Beck, Caudullo, de Rigo, \& Tinner, 2016) that tolerates an extremely wide range of climatic and edaphic conditions. In its native range, silver birch supports a large community of insect herbivores, especially lepidopteran and hymenopteran (i.e. sawflies) leaf chewers and miners (Atkinson, 1992; Beck et al., 2016; Zúbrik, Kunca, \& Csóka, 2013).

\section{Plot and tree selection in TreeDivNet experiments}

TreeDivNet consists of 27 long-term tree diversity experiments specifically designed to investigate the effects of tree species diversity on forest functioning (Grossman et al., 2018; Paquette et al., 2018; Verheyen et al., 2016). Because the experiments are globally distributed, TreeDivNet is particularly well suited to explore how tree diversity effects on herbivory vary with climate. We collected data from twelve sites belonging to six tree diversity experiments where silver birch was present (Fig. 1; Supporting Information Table S1). These sites encompassed temperate and boreal biomes of the northern hemisphere and spanned over 17 decimal degrees in latitude, covering about half of the latitudinal span of silver birch (Beck et al., 2016). At each site, we selected silver birch monoculture plots and mixed species plots where silver birch was present. Tree species richness in those mixtures ranged from two to six species (including silver birch) and included broadleaved or coniferous species, or a mix of both. The species composition of mixture plots varied among sites. At certain sites, species composition types were replicated in two to three blocks. We randomly selected three to five birch trees in the core area of each experimental plot (i.e. avoiding border trees to limit edge effects). The final dataset was derived from 564 trees planted in 157 plots. 


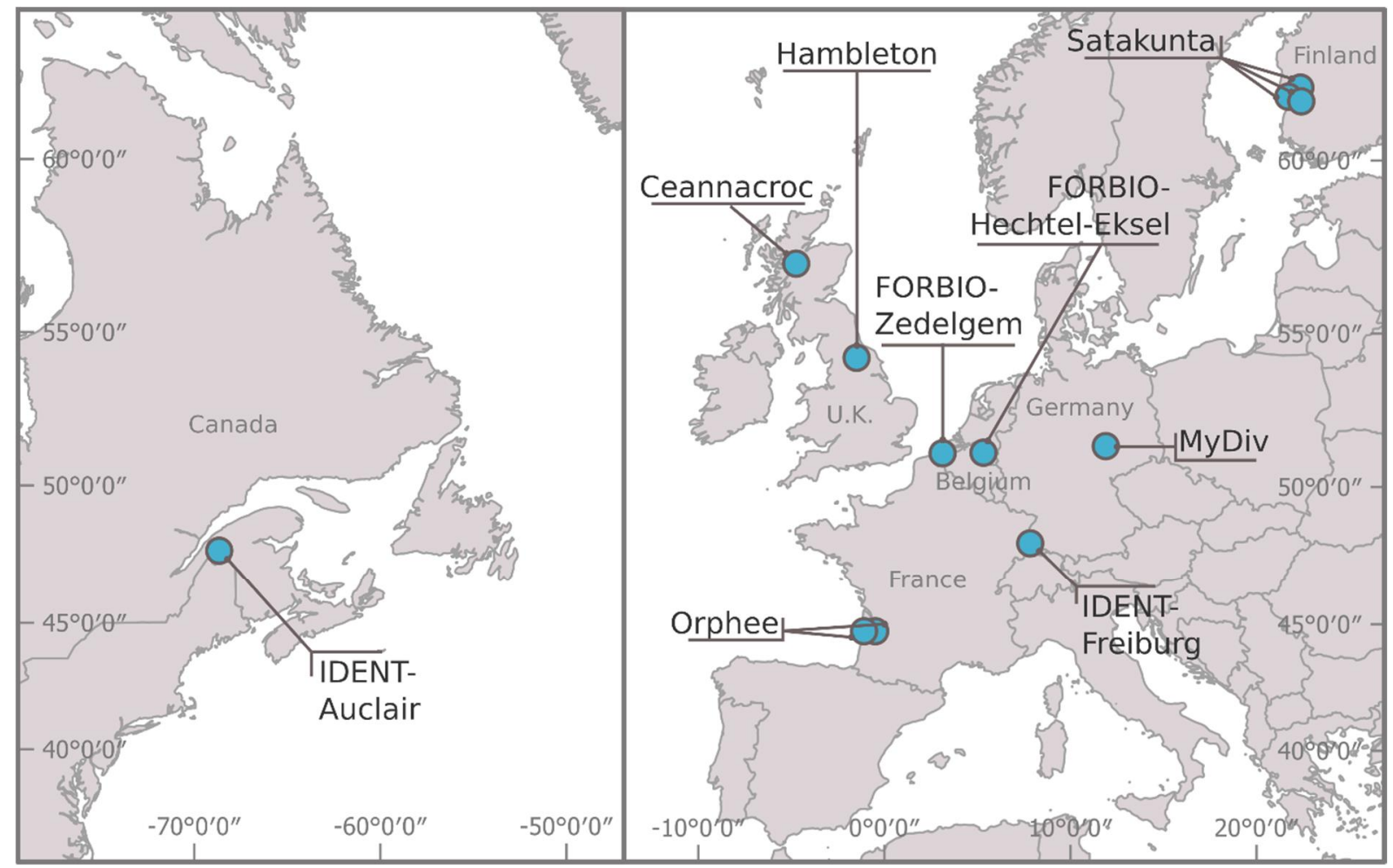

Figure 1. Map of the TreeDivNet experimental sites included in the study.

\section{Leaf collection and damage assessment}

190

191

192

193

194

195

196

197

198

199

200

201

202

203

Fifty leaves per birch tree were haphazardly sampled in mid-July 2017 (2014 for the three Finnish sites). We assessed insect leaf herbivory as the overall percentage of leaf area removed by three common feeding guilds of insect herbivores: chewers, miners and skeletonizers. We assigned each leaf to one of seven classes of damage: (A) $0 \%$ of leaf area removed, (B) 1 to 5\%, (C) 6 to 15\%, (D) 16 to 25\%, (E) 26 to 50\%, (F) 51 to 75\%, and (G) 76 to $100 \%$. To reduce unconscious bias in insect herbivory assessment, we split leaves from each tree into two equal pools that were separately processed by two independent observers unaware of leaf origin. Then, we aggregated insect herbivory estimates at the tree level by averaging the median values of damage class of all leaves. In the case of the three Finnish sites (Satakunta areas 1, 2 and 3), the methodology differed slightly but was still consistent (see Muiruri et al., 2019). On average, insect herbivores damaged 3.91\% ( $\pm 2.60 \%$ ) of leaf area (damages ranged from 0.36 to $13.03 \%$ of leaf area; Supporting Information Table S2). We are confident that we did not underestimate herbivory by overlooking missing leaves since leaves did not start falling at the sampling time. The observed levels of insect herbivory were low and 
comparable with those observed in other studies on silver birch (e.g. Castagneyrol et al., 2018; Kozlov et al., 2015; Muiruri, Milligan, Morath, \& Koricheva, 2015; Muiruri et al., 2019).

\section{Phylogenetic isolation}

Given that tree species diversity effects on herbivores can be affected by phylogenetic dissimilarity between the tree species in the mixture, we used phylogenetic information to account for differences in tree species composition of mixed stands across the experiments (Srivastava et al., 2012). Many metrics have been developed to characterize phylogenetic diversity of a pool of species (Miller, Farine, \& Trisos, 2017). Here, we were primarily interested in the phylogenetic contrast between $B$. pendula and associated species in the mixtures. We therefore used evolutionary distinctiveness (ED), that is a species-specific metric described by Redding and Mooers (2006), to estimate phylogenetic isolation of silver birch from other tree species present in each plot.

We used the phylomatic function from the brranching package in R (with tree R20120829; Chamberlain, 2018) to obtain an overall phylogenetic tree comprising the overall pool of tree species (Supporting Information Fig. S1). Node ages down to family level were derived from Magallón, Gómez-Acevedo, Sánchez-Reyes and Hernández-Hernández (2015). Genus node ages were approximated by dividing the length of the edge from the family node to the tip by two. The same was subsequently done for species nodes considering edge length from the genus node to the tip. For each plot, we pruned the overall phylogenetic tree to obtain a subtree corresponding to the pool of tree species present in the plot. Then, birch ED was calculated using the evol.distinct function (equal splits method; Redding \& Mooers, 2006; Redding et al., 2008) from the picante package (Kembel et al., 2010) in R, as follows:

$$
\operatorname{BirchED} D_{(T)}=0.5^{n} \sum_{e \in s(T, R)}^{R} L_{e}
$$

where $\mathrm{T}$ is the phylogenetic tree for the pool of tree species present in the plot, $R$ the root of the phylogenetic tree, $e$ an edge along the path from the root of the tree to the $B$. pendula tip, $L$ the length of the edge $e$ and $n$ the number of nodes between the edge $e$ and the $B$. pendula tip. Low and high ED values correspond to low and high phylogenetic isolation, respectively. Birch ED was positively correlated with species richness (see Supporting Information Fig. S2) 
and ranged from 12.15 million years in birch monocultures (which corresponds to the length of the edge from B. pendula-Betula papyrifera bifurcation to B. pendula tip) to 324.40 million years in mixed plots where birch was associated with coniferous species only.

\section{Climate data}

We extracted mean annual temperature and total annual rainfall averaged over the 19792013 period (hereafter referred to as "temperature" and "rainfall" respectively) for each study site using the Climatologies at High resolution for the Earth's Land Surface Areas dataset (CHELSA; Karger et al., 2017; Supporting Information Fig. S3a). In the ORPHEE experiment, half of the plots were located in irrigated blocks sprinkled with $3 \mathrm{~mm}$ of water per night from May to October. An annual surplus of $552 \mathrm{~mm}$ was thus added to the rainfall amount obtained from the CHELSA database in these plots. To account for this additional irrigation treatment, data collected in the ORPHEE experiment were considered as data from two distinct sites (irrigated vs non-irrigated). Overall, our network of tree diversity experiments covered a $17^{\circ}$ latitudinal gradient and encompassed $10^{\circ} \mathrm{C}$ of variation in the mean annual temperature and $964 \mathrm{~mm}$ of variation in the annual rainfall.

\section{Leaf phenolics}

Leaf phenolics have been reported to confer resistance against insect herbivores in several tree species including birch (Forkner, Marquis, \& Lill, 2004; Lahtinen et al., 2004; Moreira, Galmán, Francisco, Castagneyrol, \& Abdala-Roberts, 2018b; Riipi et al., 2005) and therefore represent a suitable proxy for assessing leaf chemical defences (or leaf nutritional quality to herbivores). We quantified the concentration of phenolic compounds on a subsample of five birch leaves - with little $(<5 \%)$ or no damage - per tree, following a procedure based on ultrahigh performance liquid chromatography (as in Moreira et al., 2018b; Visakorpi, Riutta, Martinez-Bauer, Salminen, \& Gripenberg, 2019). Following drying (at $45^{\circ} \mathrm{C}$ during 72 hours) and grinding of leaves, we extracted phenolic compounds from $20 \mathrm{mg}$ of powdered dry leaf tissue with $1 \mathrm{~mL}$ of $70 \%$ methanol in an ultrasonic bath for $15 \mathrm{~min}$, followed by centrifugation (Moreira et al., 2014). We then transferred the extracts to chromatographic vials. Ultra-HighPerformance Liquid-Chromatograph (UHPLC Nexera LC-30AD; Shimadzu) equipped with a Nexera SIL-30AC injector and one SPD-M20A UV/VIS photodiode array detector was used to perform the chromatographic analyses. The compound separation was carried out on a 
Kinetex ${ }^{\mathrm{TM}} 2.6 \mu \mathrm{m}$ C18 82-102 $\AA$, LC Column $100 \times 4.6 \mathrm{~mm}$, protected with a C18 guard cartridge. The flow rate was $0.4 \mathrm{~mL} \mathrm{~min}-1$ and the oven temperature was set at $25^{\circ} \mathrm{C}$. The mobile phase consisted of two solvents: water-formic acid $(0.05 \%)(A)$ and acetonitrile-formic acid $(0.05 \%)$ (B), starting with $5 \% \mathrm{~B}$ and using a gradient to obtain $30 \% \mathrm{~B}$ at $4 \mathrm{~min}, 60 \% \mathrm{~B}$ at $10 \mathrm{~min}, 80 \% \mathrm{~B}$ at $13 \mathrm{~min}$ and $100 \% \mathrm{~B}$ at $15 \mathrm{~min}$. The injection volume was $3 \mu \mathrm{L}$. We identified four groups of phenolic compounds: flavonoids, ellagitannins and gallic acid derivates (hydrolysable tannins), proanthocyanidins (condensed tannins) and hydroxycinnamic acid (precursors to lignins). We quantified flavonoids as rutin equivalents, condensed tannins as catechin equivalents, hydrolysable tannins as gallic acid equivalents, and precursors to lignins as ferulic acid equivalents (Moreira et al., 2018a, b). Quantification of these phenolic compounds was achieved by external calibration using calibration curves at $0.25,0.5,1,2$, and $5 \mu \mathrm{gL}^{-1}$. Total phenolic concentration was equal to $334.57 \pm 107.48 \mathrm{mg} \mathrm{g}^{-1}$ of leaf dry matter on average and ranged from 13.51 to $775.08 \mathrm{mg} \mathrm{g}^{-1}$ (see Table S3 in Supporting Information for more details).

\section{Statistical analyses}

First, we used linear mixed models (LMM) to test for the effects of tree species richness and birch phylogenetic distinctiveness on insect herbivory and leaf phenolic concentration (two normally distributed response variables). To test whether tree species richness, phylogenetic distinctiveness of birch or the combination of both best predicted the response variables, we built three models for each response variable with either (i) tree species richness, (ii) birch evolutionary distinctiveness (ED) or (iii) tree species richness and birch ED (main effects plus interaction) as predictors. We calculated the Akaike Information Criterion corrected for small sample size (AICC) of each model to identify the best model - with the lowest AICc - for a given response variable (Burnham \& Anderson, 2002; Johnson \& Omland, 2004). If the AICC difference between two models was less than two, they were considered equally likely. The best herbivory and phenolic models were used in the subsequent analyses.

Second, we used LMMs to test for the effects of climate on insect herbivory and leaf phenolic concentration. For each response variable, we used the full version of the best model(s) (with the lowest $\mathrm{AICC}$ ) from the first step to which we added temperature and rainfall main effects, as well as all two- and three-ways interactions. 
Third, we tested whether the variability in insect herbivory was accounted for by phenolic concentration. Specifically, we included leaf phenolic concentration as a covariate in the full model(s) from the second step. Two-ways interactions involving leaf phenolic concentration and either temperature, rainfall or tree diversity were also included in the model(s) to test for interactive effects. By comparing results of insect herbivory models without (second step) vs with leaf phenolics (third step), we tested whether the effects of tree diversity and climate on insect herbivory were mediated by changes in leaf chemical defences. That would be the case if a significant effect of tree species diversity and/or climate on insect herbivory became nonsignificant after including leaf phenolic concentration as a covariate.

In the last two steps, full models were simplified following a backward selection approach, which consisted of sequentially dropping the terms with the lowest impact on model fit, starting with the highest order interactions. Model simplification was done by using loglikelihood tests based on a $\chi^{2}$ distribution with significance threshold set at $\alpha=0.05$.

In all models, we accounted for the hierarchical structure of data by using Plot nested within Block, nested within Site, as a random factor (i.e., 1|Site/Block/Plot in R syntax). By doing so, we also accounted for any variance explained by uncontrolled parameters (e.g., experimental design, soil properties). In all models, predictors were scaled and centred, which made it possible to compare the magnitude of the effects even when interaction terms were significant (Schielzeth, 2010). Collinearity among all predictors was found to be weak enough to limit inflation of the variance of estimated model parameters (variation inflation factors [VIFs] less than two). Model parameters were estimated by restricted likelihood estimation and the significance $(\alpha=0.05)$ of the regression coefficients was tested with Student t-tests and Satterthwaite's approximation for degrees of freedom. We evaluated model fit by calculating the percentage of variance explained by fixed $\left(R^{2}\right)$ and by fixed plus random effects $\left(R^{2}\right)$ (Nakagawa \& Schielzeth, 2013). All analyses were conducted in R (version 3.5.1; R Core Development Team, 2013) with the following packages: ImerTest (Kuznetsova, Brockhoff, \& Christensen, 2017), car (Fox \& Weisberg, 2018), and MuMIn (Barton, 2018).

Concentrations of all types of phenolic compounds were positively correlated with each other (Supporting Information Fig. S4), which made it inappropriate to use all phenolic types as predictors of insect herbivory in the same model (inflation of the variance of estimated model parameters). Concentrations of all types of phenolic compounds and concentrations of total 
phenolics co-varied with climate and diversity predictors, i.e. direction of effects were consistent across phenolic types (Table 1; Supporting Information Table S4). Based on this, we choose to present results for total phenolic concentration only.

\section{Results}

\section{Tree species diversity effects on insect herbivory and leaf phenolics}

We found no significant effect of species richness or birch evolutionary distinctiveness (ED) per se on insect herbivory, and no interactive effect of the two diversity metrics either (Table 1a). The herbivory model with species richness and the herbivory model with birch ED had the lowest AICc values, not differing by more than two units (Table 1a). These two models were thus used in the subsequent analyses while the herbivory model with both diversity metrics, which had a higher AICc value (Table 1a), was eliminated.

We found a significant negative effect of birch ED on leaf phenolic such that birch leaves were less defended when birches were more phylogenetically distinct from their neighbours (Table 1b). In contrast, we found a significant and positive effect of tree species richness on leaf phenolic concentration. The phenolics model with birch ED only had a lower AICc value than the model with species richness only (Table $1 \mathrm{~b}$ ), but both of these models had higher AICc values than the model with both diversity variables included (Table $1 \mathrm{~b}$ ). Hence, the best phenolics model that was used in subsequent analyses was the model with both species richness and birch ED.

\section{Effects of climate and tree diversity on insect herbivory}

We found that insect herbivory on birch leaves significantly increased with increasing temperature (Fig. 2a; Table 2a) both in the model with tree species richness and in the model with birch ED. Rainfall had no significant effect on insect herbivory.

The effect of tree species richness on insect herbivory was contingent upon temperature (significant species richness $\times$ temperature interaction; Table 2a). In particular, insect herbivory decreased with increasing tree species richness at low temperatures but was not affected by tree species richness at higher temperatures (Fig. 2b). In the final simplified model, tree species richness and temperature collectively explained $22 \%$ of the variability in insect herbivory $\left(R^{2} m=0.22 ; R^{2} c=0.59\right)$. By contrast, there was no significant effect of the 

birch ED and temperature collectively explained $21 \%$ of the variability in insect herbivory $\left(R^{2} \mathrm{~m}\right.$ $\left.353=0.21 ; R^{2}{ }_{c}=0.59\right)$.
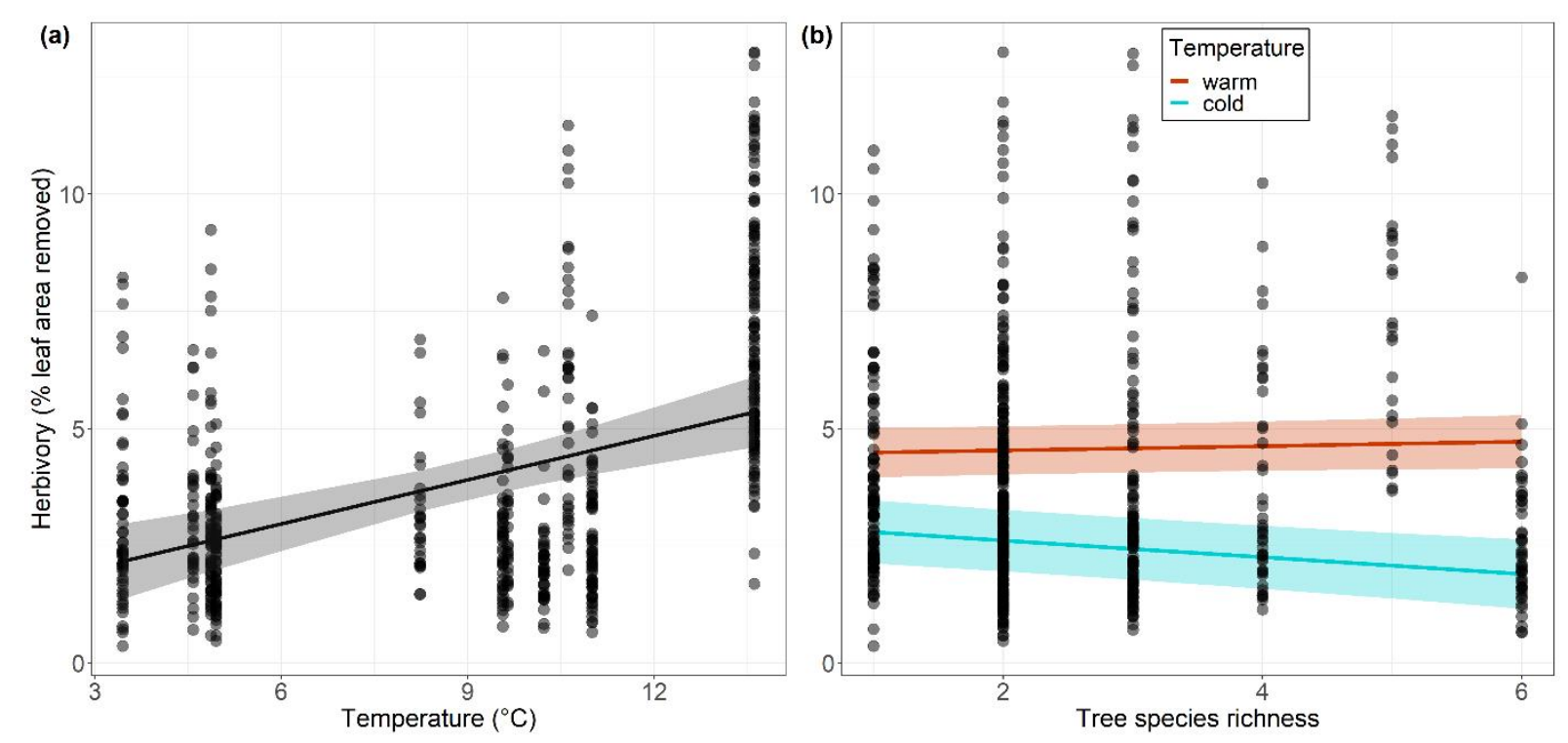

355

356

357

358

359

360

361

362

363

364

365

366

367

368

369

370

371

Figure 2. Relationships (a) between insect herbivory on silver birch leaves and mean annual temperature and (b) between insect herbivory and tree species richness for two contrasted temperature levels. The figure shows observed data (points) as well as model predictions (solid lines) and standard errors (shaded areas). In panel (a), species richness was set at a median value to compute predictions. "Warm" and "cold" temperature levels corresponded to 0.25 and 0.75 quartiles of the observed temperature range, respectively.

\section{Effects of climate and tree diversity on leaf phenolic concentration}

Leaf phenolic concentration significantly increased with increasing temperature and tended to decrease with increasing rainfall but not significantly (Table 2b; Fig 3a). In addition, leaf phenolic concentration significantly increased with species richness (Table 2b; Fig. 3b) regardless of the climate (no significant interactions with rainfall or temperature). In contrast, the effect of birch ED on leaf phenolic concentration was contingent upon temperature and rainfall conditions (significant birch ED $\times$ temperature $\times$ rainfall interaction; Table $2 b$ ). Specifically, leaf phenolic concentration decreased with increasing birch phylogenetic distinctiveness independently of the temperature at low rainfall level (Fig. 3c), but decreased more markedly with increasing phylogenetic distinctiveness of birch in warm conditions only at high rainfall level (Fig. 3d). In the final simplified model, climate and tree species diversity 
372 collectively explained $46 \%$ of the variability in phenolic concentration of birch leaves $\left(R^{2} \mathrm{~m}=\right.$ $\left.373 \quad 0.46 ; R^{2}{ }_{c}=0.67\right)$.
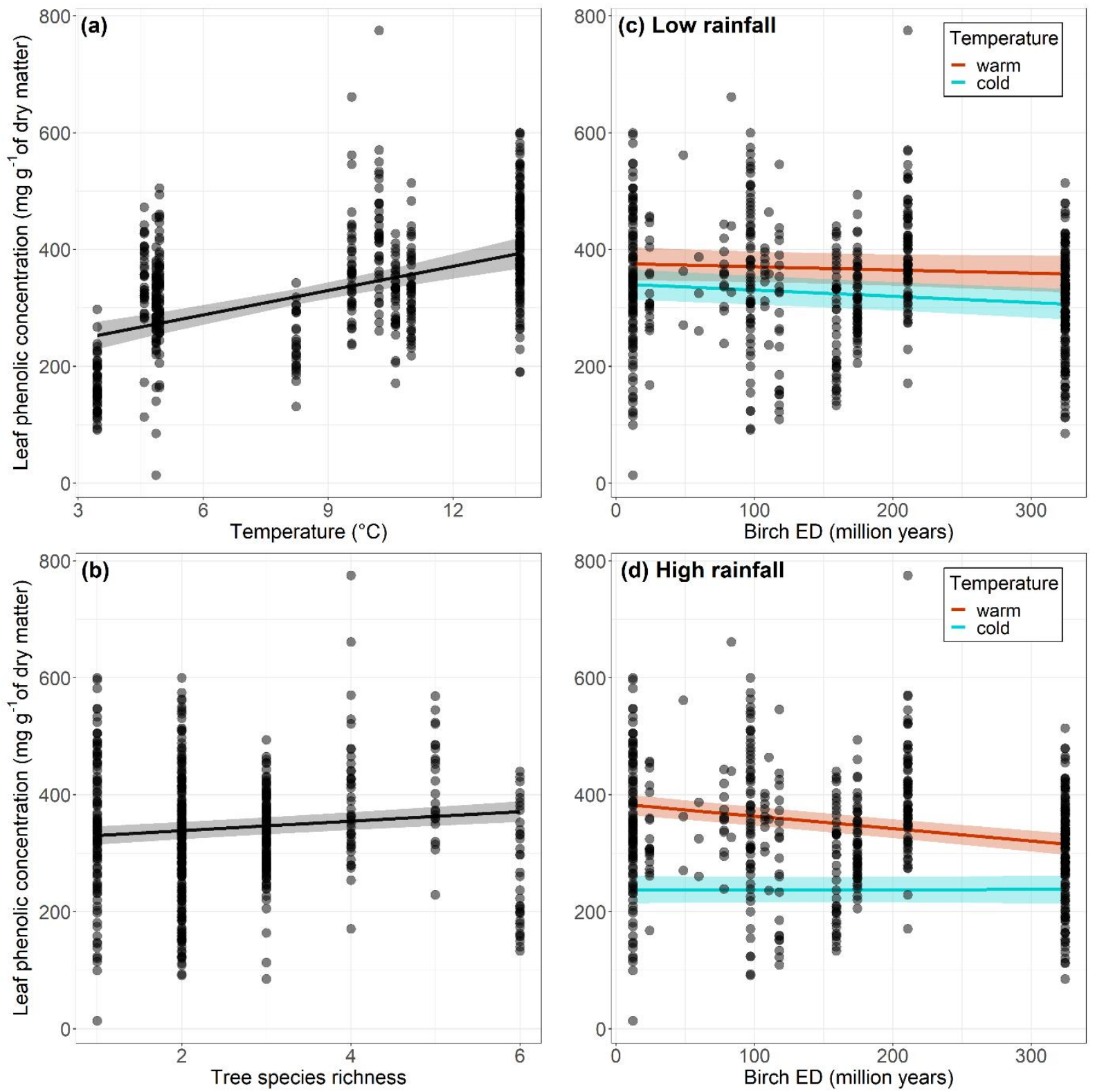

375 Figure 3. Leaf phenolic concentration in birch leaves as a function of (a) temperature, (b) tree species richness and as a function of birch evolutionary distinctiveness (ED) for two contrasted levels of temperature under two contrasted levels of rainfall ( $c$ and $d$ ). The figure shows observed data (points) as well as model predictions (solid lines) and standard errors (shaded areas). "Warm" and "cold" temperature levels corresponded to 0.25 and 0.75 quartiles of the observed temperature range, respectively. "Low" and "high" rainfall levels corresponded to 0.25 and 0.75 quartiles of the observed rainfall range, respectively. The predictors that were not involved in the relationships shown were set at median values to compute predictions. 
384

385

386

387

388

389

390

391

392

393

394

395

396

397

398

399

400

401

When we included leaf phenolic concentration as a covariate in the herbivory models - with either species richness or birch ED - we found that insect herbivory decreased with increasing leaf phenolic concentration in both cases (Table 3; Fig. 4a). In the two models, the positive effect of temperature on insect herbivory remained significant (Table 3), which indicated that the effect of temperature on insect herbivory was not mediated by leaf phenolics.

In the herbivory model with species richness, we found that the effect of species richness that was contingent upon temperature - became non-significant after including leaf phenolic concentration as a covariate (Table 3), indicating that the effect of tree species richness on insect herbivory was mediated by leaf phenolics. Temperature and leaf phenolic concentration collectively explained $24 \%$ of the variability in insect herbivory $\left(R^{2}{ }_{m}=0.24 ; R^{2}\right.$ $=0.58)$.

In the herbivory model with birch ED, we found that birch ED effect on insect herbivory was contingent upon phenolic concentration in birch leaves (significant birch ED $\mathrm{x}$ phenolic concentration interaction, Table 3). In particular, when birch leaves had low phenolic concentration, insect herbivory decreased with increasing birch ED, while when birch leaves had high phenolic concentration insect herbivory increased with increasing birch ED (Fig. 4b). Temperature, birch ED and leaf phenolic concentration collectively explained $25 \%$ of the variability in insect herbivory $\left(R^{2}=0.25 ; R^{2}{ }_{c}=0.59\right)$.
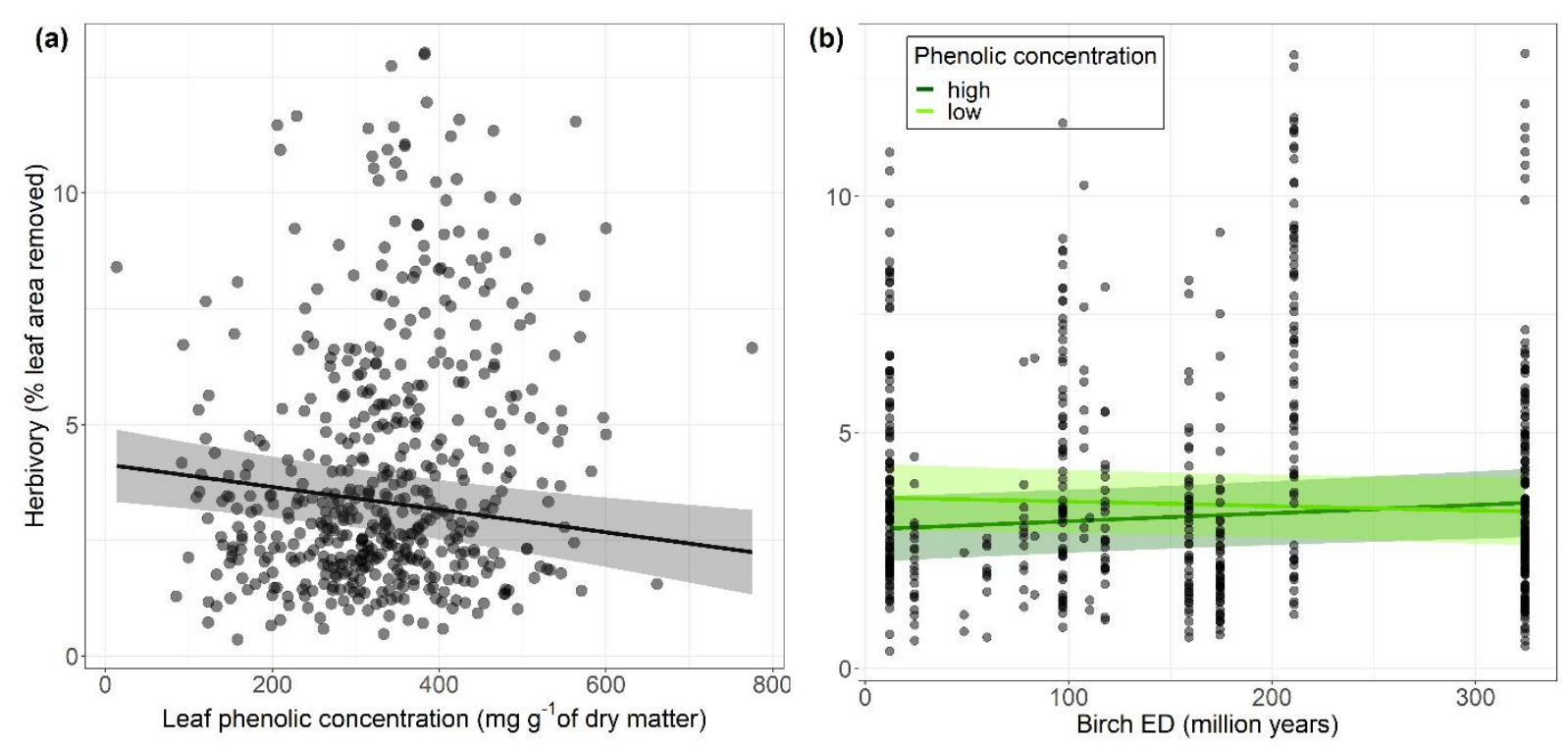

402 
Figure 4. Relationship (a) between insect herbivory and leaf phenolic concentration and (b) between insect herbivory and birch evolutionary distinctiveness (ED) for different levels of leaf phenolic concentration. The figure shows observed data (points) as well as model predictions (solid lines) and standard errors (shaded areas). "Low" and "high" phenolic concentration levels corresponded to 0.25 and 0.75 quartiles of the observed phenolic concentration range, respectively. The predictors that were not involved in the relationships shown were set at median values to compute predictions.

\section{Discussion}

With this study, we showed that the effect of tree species diversity on insect herbivory on silver birch leaves, i.e. associational effects, were climate-dependent and, in particular, varied with temperature. Our findings also showed that tree species diversity modified chemical defence levels in birch leaves and further suggested that such changes in leaf chemistry induced by heterospecific neighbours were partly climate-dependent. Finally, we found that associational effects were mediated by changes in defences under certain climatic conditions. Below we discuss mechanisms underlying the observed patterns.

\section{Effects of tree diversity on insect herbivory are climate dependent}

We found no significant effects of either tree species richness or birch phylogenetic distinctiveness per se on background levels of insect herbivory on birch. In fact, we found evidence that tree diversity effects on herbivory were dependent on climate. This result could partly explain the variable effects of tree diversity on herbivory previously reported in the literature (Brezzi, Schmid, Niklaus, \& Schuldt, 2017; Castagneyrol et al., 2014; Jactel et al., in press; Kambach et al., 2016; Ness et al., 2011; Ratcliffe et al., 2017; Schuldt et al., 2010, 2014, 2015; Vehviläinen, Koricheva, \& Ruohomäki, 2007; Wein et al., 2016) including in studies focusing on birch trees (Castagneyrol et al., 2018; Haase et al., 2015; Muiruri et al., 2015, 2019; Setiawan, Vanhellemont, Baeten, Dillen, \& Verheyen, 2014). Specifically, we provided evidence for changes in associational effects along the mean annual temperature gradient: associational resistance of birch to insect herbivory occurred in cold conditions whereas no associational effects could be detected in warm conditions. The mitigation of associational resistance with increasing temperature could be due to the higher proportion of generalist (vs specialist) herbivore species in warmer regions (Forister et al., 2015), that are less affected or even benefit from plant diversity (Castagneyrol et al., 2014; Jactel \& Brockerhoff, 2007). This finding might also be explained by the greater abundance and activity of herbivores in warmer 
climate that may in turn lower the resistance of mixed plant communities to herbivores. Supporting this view, associational resistance to the bean beetle, Callosobruchus maculatus, was found to decrease with the population density of this herbivore, likely because of conspecific avoidance behaviour (Merwin, Underwood, \& Inouye, 2017; but see FernandezConradi, Jactel, Hampe, Leiva, \& Castagneryol, 2017). Higher herbivore density may also increase the probability for a host tree to be located and attacked, simply because proportionally more individuals will pass through the net of resistance mechanisms (e.g. resource concentration effect, host-finding disruption or predation by natural enemies), resulting in lower apparent resistance to herbivores. In support of this density-dependence hypothesis, our results showed that background insect herbivory on birch leaves, although low, markedly increased with increasing mean annual temperature (Kozlov et al., 2015; Wang et al., 2016). Several mechanisms have been proposed to explain the positive effect of temperature on herbivory, including direct effects on herbivores' developmental rate, winter survival and activity and indirect effects through reduced plant nutritional quality inducing compensatory feeding (Bale et al., 2002; Bauerfeind \& Fisher, 2013; Garibaldi, Kitzberger, \& Ruggiero, 2011; Klapwijk, Ayres, Battisti, \& Larsson, 2012).

We found no effect of rainfall on insect herbivory, neither directly nor through changes in the herbivore response to tree diversity. Yet, drought-induced water stress is known to increase tree susceptibility to defoliators (Carnicer et al., 2011; Jactel et al., 2012), and a previous study reported an increase in insect herbivory on birch under drought (Castagneyrol et al., 2018). We could not assess the effect of drought per se in the present study, and it is possible that annual rainfall does not reflect water availability to trees because of site-specific topology or edaphic conditions. Besides, ectophagous (skeletonizers and chewers) and endophagous (miners) herbivores may respond inconsistently to rainfall conditions because they live on the surface $v s$ inside the leaves, which could also explain the absence of an overall response since we pooled the two groups. Therefore, the lack of effect of rainfall on herbivory in the present study should be interpreted with caution and this question should be further explored.

\section{Levels of leaf defences are shaped by both tree diversity and climate}

Our results showed that tree diversity modifies leaf chemistry of focal birches - and hence their quality for herbivores. Specifically, the concentration of leaf phenolics increased with increasing tree species richness, but decreased with increasing birch evolutionary 
distinctiveness, used as a proxy for birch functional distinctiveness in experimental plots (Srivastava et al., 2012). Positive effect of plant species diversity on plant chemical defences have been previously reported in birch (Castagneyrol et al., 2018; Muiruri et al., 2019) and other plant species (Bustos-Segura, Poelman, Reichelt, Gershenzon, \& Gols, 2017; Kostenko, Mulder, Courbois, \& Bezemer, 2017; Moreira et al., 2014; Mraja, Unsicker, Reichelt, Gershenzon, \& Roscher, 2011). The underlying mechanisms however are poorly understood and the opposing effects of species richness and functional diversity suggest they are complex. On the one hand, defence induction in richer plant community could arise in response to greater herbivory (Karban \& Baldwin, 1997) due to associational susceptibility. However, herbivore-mediation of species richness effects on defences seems unlikely in our case since our results mainly report associational resistance (Fig. 2b) and we found a negative association between herbivory and defence concentration (Fig. 4a). On the other hand, it is plausible that the production of leaf phenolics reflected a trade-off between growth and defences whereby increased allocation to growth in plots with functionally dissimilar species (e.g. through complementarity or facilitation) leads to a concomitant reduction in defence investment (Bryant, Chapin, \& Klein, 1983; Herms \& Mattson, 1992). In this sense, studies have reported that experimental manipulation of resource availability (e.g. nutrients or water) can lead to concomitant and opposite modulations of growth and defence production (Gutbrodt et al., 2012; Lange et al., 2019). This process could be particularly strong in birch, a fast-growing, resource-acquisitive species. Consistently, a recent study found that tree species composition affected leaf chemistry in birch, with less defence compounds in phylogenetically more diverse mixtures (Castagneyrol et al., 2018).

A meta-analysis by Koricheva, Larsson, Haukioja and Keinänen (1998) supports the view that tree diversity primarily affects the local abiotic conditions (specifically nutrient, water or light availability) and that such effects subsequently shape plant secondary chemistry. In particular, studies have demonstrated that crown illumination can affect leaf chemical composition, with shading associated with lower carbohydrate and phenol concentrations in leaves of birch trees (Henriksson et al., 2003) and other species (Larsson, Wirén, Lundgren, \& Ericsson, 1986; Mole, Ross, \& Waterman, 1988). The opposing effects of tree species richness and birch phylogenetic distinctiveness on birch leaf phenolics could both relate to the relative heights or growth rates of the trees present in the plots and the light available to birch trees. Indeed, birch is a fast- 
growing, early successional species that is expected to be more shaded in monocultures or in plots where it is present at high density (self-shading), than in mixtures where it is present at lower density and mixed with slow-growing tree species. In our study, species richness increase was correlated with the probability to include broadleaved species growing slower than birch trees and with a reduction of birch proportion (Supplementary Materials Figs S1 and S2). Hence, the positive effect of species richness on leaf phenolic concentration in birch leaves might be explained by a reduction of shading in species-richer mixtures. On the opposite, the increase of birch phylogenetic distinctiveness was correlated with the proportion of fast growing coniferous ( $v s$ broadleaved) neighbours such as larches or pines (Supplementary Materials Figs S1 and S2) that were generally taller than birch trees. The decrease of leaf phenolic concentration with birch phylogenetic distinctiveness could therefore result from lower light availability in plots where birch is more phylogenetically isolated (mixed with a greater proportion of conifers). However, birches are able to adapt their crown architecture to better compete with their neighbours for light acquisition (Lintunen \& Kaitaniemi, 2010), therefore potentially limiting the impact of neighbours on crown illumination and leaf chemistry and explaining the relatively low phenolic concentration changes observed along tree diversity gradients.

Because our study was not designed to determine the mechanisms underlying neighbourinduced changes in leaf chemical defences, nor did it include tree growth or abiotic factors measurements, our lines of arguments are mostly speculative. Few studies have explicitly addressed the implication of growth-defence trade-offs in associational effects and they were inconclusive (Moreira et al., 2014; Rosado-Sánchez, Parra-Tabla, Betancur-Ancona, Moreira, \& Abdala-Roberts, 2017). Future studies should specifically investigate the role that tree relative heights and architectures play in neighbour-induced changes of focal species chemistry.

We found that the concentration of chemical defences increased with temperature, which contrasts with the results of previous studies on oaks and birches in temperate and boreal biomes (Kuokkanen et al., 2001; Moreira et al., 2018a). Although there is ample literature on the variation of plant defences along climatic gradients, there is no consensus on the strength and direction of this relationship (Moles et al., 2011). Interestingly, we showed that climate also affected leaf phenolic concentration indirectly by modulating the tree diversity-defences 
relationships. Specifically, decrease in chemical defence levels of birch associated with greater tree phylogenetic diversity were stronger in warm and humid conditions. This indicates that climate and tree species composition jointly determined tree investment in chemical defences, likely through growth-defence trade-offs.

\section{Do leaf chemical defences mediate effects of climate and diversity on insect herbivory?}

We found a negative relationship between leaf phenolic concentration and insect herbivory, supporting the view that these secondary metabolites act as defences against herbivores (in addition to being involved in other physiological processes; Forkner et al., 2004; Harborne \& Williams, 2000; Lahtinen et al., 2004).

We found evidence that the effect of temperature on leaf herbivory was independent of the level of chemical defences. However, our results showed that the interactive effects of temperature and tree species richness on insect herbivory were mediated by changes in leaf chemical defence levels. This finding suggests that defence-mediated associational effects on insect herbivory are also climate-dependent. In our case, such effects were only observed in cold climates where chemical defences levels were low and where an increase in defences may have a stronger effect on background insect herbivory levels.

We found that the effect of birch phylogenetic distinctiveness on herbivory varied with the levels of chemical defences in birch leaves. Specifically, associational effects shifted from resistance to susceptibility with the increase of leaf phenolics concentration. This finding suggests that mechanisms involved in birch associational resistance against herbivores, other than chemical defence, might have been at play (e.g. host-finding disruption, and resource dilution), and that an undetermined factor was simultaneously controlling the concentration of leaf chemical defences and interfering with these mechanisms. Forest structure, and more specifically relative heights of tree species, may for instance influence at the same time (i) leaf chemistry of a focal species by affecting crown illumination (Koricheva et al., 1998) and the synthesis of photo-protective flavonoids (Agati \& Tattini, 2010) and (ii) the apparency of this focal species to herbivores (Castagneyrol et al., 2019; Damien et al., 2016). In addition, nutrient availability may affect growth of trees and the concentration of carbon-based defences in leaves (Bryant et al., 1983; Koricheva et al., 1998). In turn, tree growth, as jointly determined by tree diversity (the relative competitive ability of the species) and nutrient 
availability, could affect apparency of the focal species to herbivores, as well as the abundance and diversity of canopy arthropods (Stone, Gehring, \& Whitham, 2010) with consequences for multitrophic interactions.

\section{Conclusion}

By taking advantage of an international network of tree diversity experiments and a standardized sampling protocol, we addressed the independent and interactive effects of tree species diversity and climate on tree-herbivore interactions in temperate and boreal forests. Altogether, our findings show that insect herbivory depends on a complex interplay between tree species diversity and climatic conditions, and that diversity effects on insect herbivory are partially mediated by neighbour-induced changes in leaf chemical defences. Our findings also confirm that tree species diversity can modify leaf chemistry of a focal species - and hence its quality for herbivores - but further suggest that such neighbour-induced changes are dependent on climate. Nevertheless, our approach remains correlative in essence and the ecological mechanisms underlying such patterns need to be further elucidated. In particular, future studies should be specifically designed to investigate whether diversity and climate interactively shape leaf chemistry of a focal host plant because they jointly influence resource availability and their allocation to growth vs defences by trees. Our study also supports the view that the phylogenetic or functional diversity of tree species is complementary to species richness in predicting tree-herbivore relationships, likely because it accounts for additional information relative to niche differentiation and functional dissimilarities between tree species. Finally, our findings suggest that tree diversity effects on herbivory levels should be viewed as a balance between multiple processes arising from different attributes of tree diversity (inter-specific variation of different traits). Future research should investigate which traits of tree species drive associational effects on herbivory and address simultaneously multiple underlying mechanisms. For instance, it would be particularly interesting to explore the role of forest structure and tree spatial arrangement in associational effects, as it may be implied in both neighbour-induced changes in chemical defences through effects on individual crown illumination, as well as in focal plant apparency. Importantly, the climatic context in which plant-herbivore interactions occur should be accounted for in future studies for a better understanding of the processes at play. By doing so, the study of tree diversity effects on tree resistance to insect herbivores interactions will move toward a more predictive framework. 


\section{Acknowledgments}

We thank all the TreeDivNet partners for data collection. This study was funded by the "Diversity and Productivity of Trees in the context of Climate Change" project (DiPTiCC, Grant ANR-16-CE32-0003-01). NE, OF, and FG acknowledge financial support by the German Centre for Integrative Biodiversity Research Halle-Jena-Leipzig, funded by the German Research Foundation (FZT 118), and NE and OF received support from the European Research Council (ERC) under the European Union's Horizon 2020 research and innovation program (grant agreement no. 677232 to NE).

\section{Author contributions}

$B C$ and $\mathrm{HJ}$ designed the study. $\mathrm{HJ}, \mathrm{NB}, \mathrm{JB}, \mathrm{NE}, \mathrm{OF}, \mathrm{FG}, \mathrm{DG}, \mathrm{JK}, \mathrm{BMa}, \mathrm{EM}, \mathrm{BMu}, \mathrm{CN}, \mathrm{AP}, \mathrm{QP}, \mathrm{MSL}$, VS, MS, KV and BC collected data. XM and MF performed phenolics analysis. CP computed extra data, extracted climatic data and run the analysis. $C P, B C, H J, X M$ and JK wrote the first draft. All co-authors contributed substantially to subsequent revisions.

\section{Data availability}

Data are available from the Data INRAe repository: https://doi.org/10.15454/SHCUXW.

\section{References}

Abdala-Roberts, L., Moreira, X., Rasmann, S., Parra-Tabla, V., \& Mooney, K. A. (2016). Test of biotic and abiotic correlates of latitudinal variation in defences in the perennial herb Ruellia nudiflora. Journal of Ecology, 104(2), 580-590. doi: 10.1111/1365-2745.12512

Agati, G., \& Tattini, M. (2010). Multiple functional roles of flavonoids in photoprotection: Letters. New Phytologist, 186(4), 786-793. doi: 10.1111/j.1469-8137.2010.03269.x

Anstett, D. N., Chen, W., \& Johnson, M. T. J. (2016). Latitudinal Gradients in Induced and Constitutive Resistance against Herbivores. Journal of Chemical Ecology, 42(8), 772-781. doi: 10.1007/s10886-016$\underline{0735-6}$

Atkinson, M. D. (1992). Betula Pendula Roth (B. Verrucosa Ehrh.) and B. Pubescens Ehrh. Journal of Ecology, 80(4), 837. doi: $10.2307 / 2260870$

Bale, J. S., Masters, G. J., Hodkinson, I. D., Awmack, C., Bezemer, T. M., Brown, V. K., ... Whittaker, J. B. (2002). Herbivory in global climate change research: direct effects of rising temperature on insect herbivores. Global Change Biology, 8(1), 1-16. doi: 10.1046/j.1365-2486.2002.00451.x

Barbosa, P., Hines, J., Kaplan, I., Martinson, H., Szczepaniec, A., \& Szendrei, Z. (2009). Associational Resistance and Associational Susceptibility: Having Right or Wrong Neighbors. Annual Review of Ecology, Evolution, and Systematics, 40(1), 1-20. doi: 10.1146/annurev.ecolsys.110308.120242

Barton, K. (2018). MuMIn: Multi-Model Inference. R package version 1.42.1 (Version 1.42.1). Retrieved from https://CRAN.R-project.org/package=MuMln

Bauerfeind, S. S., \& Fischer, K. (2013). Increased temperature reduces herbivore host-plant quality. Global Change Biology, 19(11), 3272-3282. doi: 10.1111/gcb.12297

Beck, P., Caudullo, G., de Rigo, D., \& Tinner, W. (2016). Betula pendula, Betula pubescens and other birches in Europe: distribution, habitat, usage and threats. In J. San-Miguel-Ayanz, D. de Rigo, G. 
Caudullo, T. Houston Durrant, \& A. Mauri (Eds.), European Atlas of Forest Tree Species (pp. 70-73). Luxembourg: Publication Office of the European Union.

Bernays, E., \& Bright, K. (1993). Mechanisms of dietary mixing in grasshoppers: A review. Comparative Biochemistry and Physiology Part A: Physiology, 104(1), 125-131. doi: 10.1016/0300-9629(93)90019$\underline{Z}$

Brezzi, M., Schmid, B., Niklaus, P. A., \& Schuldt, A. (2017). Tree diversity increases levels of herbivore damage in a subtropical forest canopy: evidence for dietary mixing by arthropods? Journal of Plant Ecology, 10(1), 13-27. doi: 10.1093/jpe/rtw038

Bryant, J. P., Chapin, F. S., \& Klein, D. R. (1983). Carbon/Nutrient Balance of Boreal Plants in Relation to Vertebrate Herbivory. Oikos, 4O(3), 357-368. doi: $10.2307 / 3544308$

Burnham, K. P., \& Anderson, D. R. (2002). Model selection and multi-modal inference: A practical information theoretic approach (Second edition, Vol. 2). New-York, NY: Springer.

Bustos-Segura, C., Poelman, E. H., Reichelt, M., Gershenzon, J., \& Gols, R. (2017). Intraspecific chemical diversity among neighbouring plants correlates positively with plant size and herbivore load but negatively with herbivore damage. Ecology Letters, 20(1), 87-97. doi: 10.1111/ele.12713

Cardinale, B. J., Matulich, K. L., Hooper, D. U., Byrnes, J. E., Duffy, E., Gamfeldt, L., ... Gonzalez, A. (2011). The functional role of producer diversity in ecosystems. American Journal of Botany, 98(3), 572-592. doi: $\underline{10.3732 / a j b .1000364}$

Carnicer, J., Coll, M., Ninyerola, M., Pons, X., Sanchez, G., \& Penuelas, J. (2011). Widespread crown condition decline, food web disruption, and amplified tree mortality with increased climate changetype drought. Proceedings of the National Academy of Sciences, 108(4), 1474-1478. doi: $\underline{10.1073 / \text { pnas. } 1010070108}$

Castagneyrol, B., Giffard, B., Péré, C., \& Jactel, H. (2013). Plant apparency, an overlooked driver of associational resistance to insect herbivory. Journal of Ecology, 101(2), 418-429. doi: 10.1111/1365$\underline{2745.12055}$

Castagneyrol, B., Jactel, H., \& Moreira, X. (2018). Anti-herbivore defences and insect herbivory: Interactive effects of drought and tree neighbours. Journal of Ecology, 106(5), 2043-2057. doi: $\underline{10.1111 / 1365-2745.12956}$

Castagneyrol, B., Jactel, H., Vacher, C., Brockerhoff, E. G., \& Koricheva, J. (2014). Effects of plant phylogenetic diversity on herbivory depend on herbivore specialization. Journal of Applied Ecology, 51(1), 134-141. doi: 10.1111/1365-2664.12175

Castagneyrol, B., Kozlov, M. V., Poeydebat, C., Toïgo, M., \& Jactel, H. (2019). Associational resistance to a pest insect fades with time. Journal of Pest Science, 93(1), 427-437. doi: 10.1007/s10340-019$\underline{01148-y}$

Chamberlain, S. (2018). brranching: Fetch 'Phylogenies'from Many Sources. R package version 0.3.0 (Version 0.3.0) [R]. Retrieved from https://CRAN.R-project.org/package=brranching

Coley, P. D., Bryant, J. P., \& Chapin, F. S. (1985). Resource Availability and Plant Antiherbivore Defense. Science, 230(4728), 895-899. doi: 10.1126/science.230.4728.895

Damien, M., Jactel, H., Meredieu, C., Regolini, M., van Halder, I., \& Castagneyrol, B. (2016). Pest damage in mixed forests: Disentangling the effects of neighbor identity, host density and host apparency at different spatial scales. Forest Ecology and Management, 378, 103-110. doi: $\underline{10.1016 / \text { i.foreco.2016.07.025 }}$

Dinnage, R. (2013). Phylogenetic diversity of plants alters the effect of species richness on invertebrate herbivory. Peerj, 1, e93. doi: $10.7717 /$ peeri.93 
Endara, M.-J., \& Coley, P. D. (2011). The resource availability hypothesis revisited: a meta-analysis. Functional Ecology, 25(2), 389-398. doi: 10.1111/i.1365-2435.2010.01803.x

Feeny, P. P. (1976). Plant apparency and chemical defense. Recent Advances in Phytochemistry, 10, 140.

Fernandez-Conradi, P., Jactel, H., Hampe, A., Leiva, M. J., \& Castagneyrol, B. (2017). The effect of tree genetic diversity on insect herbivory varies with insect abundance. Ecosphere, 8(1), e01637. doi: $\underline{10.1002 / e c s 2.1637}$

Forister, M. L., Novotny, V., Panorska, A. K., Baje, L., Basset, Y., Butterill, P. T., ... Dyer, L. A. (2015). The global distribution of diet breadth in insect herbivores. Proceedings of the National Academy of Sciences of the United States of America, 112(2), 442-447. doi: 10.1073/pnas.142304211

Forkner, R. E., Marquis, R. J., \& Lill, J. T. (2004). Feeny revisited: condensed tannins as anti-herbivore defences in leaf-chewing herbivore communities of Quercus. Ecological Entomology, 29(2), 174-187. doi: 10.1111/j.1365-2311.2004.0590.x

Fox, J., \& Weisberg, S. (2018). An R companion to applied regression (Third Edition). Thousand Oaks, CA: Sage Publications.

Garibaldi, L. A., Kitzberger, T., \& Ruggiero, A. (2011). Latitudinal decrease in folivory within Nothofagus pumilio forests: dual effect of climate on insect density and leaf traits? Global Ecology and Biogeography, 20(4), 609-619. doi: 10.1111/j.1466-8238.2010.00623.x

Grossman, J. J., Vanhellemont, M., Barsoum, N., Bauhus, J., Bruelheide, H., Castagneyrol, B., ... Verheyen, K. (2018). Synthesis and future research directions linking tree diversity to growth, survival, and damage in a global network of tree diversity experiments. Environmental and Experimental Botany, 152, 68-89. doi: 10.1016/j.envexpbot.2017.12.015

Gutbrodt, B., Dorn, S., \& Mody, K. (2012). Drought stress affects constitutive but not induced herbivore resistance in apple plants. Arthropod-Plant Interactions, 6(2), 171-179. doi: 10.1007/s11829-011$\underline{9173-0}$

Haase, J., Castagneyrol, B., Cornelissen, J. H. C., Ghazoul, J., Kattge, J., Koricheva, J., ... Jactel, H. (2015). Contrasting effects of tree diversity on young tree growth and resistance to insect herbivores across three biodiversity experiments. Oikos, 124(12), 1674-1685. doi: 10.1111/oik.02090

Haddad, N. M., Crutsinger, G. M., Gross, K., Haarstad, J., Knops, J. M. H., \& Tilman, D. (2009). Plant species loss decreases arthropod diversity and shifts trophic structure. Ecology Letters, 12(10), 10291039. doi: $10.1111 /$ i.1461-0248.2009.01356.x

Hambäck, P. A., Inouye, B. D., Andersson, P., \& Underwood, N. (2014). Effects of plant neighborhoods on plant-herbivore interactions: resource dilution and associational effects. Ecology, 95(5), 13701383. doi: $10.1890 / 13-0793.1$

Harborne, J. B., \& Williams, C. A. (2000). Advances in flavonoid research since 1992. Phytochemistry, 55(6), 481-504. doi: 10.1016/S0031-9422(00)00235-1

Henriksson, J., Haukioja, E., Ossipov, V., Ossipova, S., Sillanpaa, S., Kapari, L., \& Pihlaja, K. (2003). Effects of host shading on consumption and growth of the geometrid Epirrita autumnata: interactive roles of water, primary and secondary compounds. Oikos, 103(1), 3-16. doi: 10.1034/i.1600$\underline{0706.2003 .12306 . x}$

Herms, D., \& Mattson, W. (1992). The Dilemma of Plants - to Grow or Defend. Quarterly Review of Biology, 67(3), 283-335. doi: 10.1086/417659

Hertel, D., Strecker, T., Müller-Haubold, H., \& Leuschner, C. (2013). Fine root biomass and dynamics in beech forests across a precipitation gradient - is optimal resource partitioning theory applicable to water-limited mature trees? Journal of Ecology, 101(5), 1183-1200. doi: 10.1111/1365-2745.12124 
Iverson, A. L., Marín, L. E., Ennis, K. K., Gonthier, D. J., Connor-Barrie, B. T., Remfert, J. L., ... Perfecto, I. (2014). REVIEW: Do polycultures promote win-wins or trade-offs in agricultural ecosystem services? A meta-analysis. Journal of Applied Ecology, 51(6), 1593-1602. doi: 10.1111/1365-2664.12334

Jactel, H., Birgersson, G., Andersson, S., \& Schlyter, F. (2011). Non-host volatiles mediate associational resistance to the pine processionary moth. Oecologia, 166(3), 703-711. doi: 10.1007/s00442-0111918-z

Jactel, H., \& Brockerhoff, E. G. (2007). Tree diversity reduces herbivory by forest insects. Ecology Letters, 10(9), 835-848. doi: 10.1111/j.1461-0248.2007.01073.x

Jactel, H., Gritti, E. S., Drössler, L., Forrester, D. I., Mason, W. L., Morin, X., ... Castagneyrol, B. (2018). Positive biodiversity-productivity relationships in forests: climate matters. Biology Letters, 14(4), 20170747. doi: $10.1098 /$ rsbl.2017.0747

Jactel, H., Koricheva, J., \& Castagneyrol, B. (2019). Responses of forest insect pests to climate change: not so simple. Current Opinion in Insect Science, 35, 103-108. doi: 10.1016/j.cois.2019.07.010

Jactel, H., Moreira, X., \& Castagneyrol, B. (in press). Tree Diversity and Forest Resistance to Insect Pests: Patterns, Mechanisms and Prospects. Annual Review of Entomology.

Jactel, H., Petit, J., Desprez-Loustau, M.-L., Delzon, S., Piou, D., Battisti, A., \& Koricheva, J. (2012). Drought effects on damage by forest insects and pathogens: a meta-analysis. Global Change Biology, 18(1), 267-276. doi: 10.1111/i.1365-2486.2011.02512.x

Jactel, H., Poeydebat, C., van Halder, I., \& Castagneyrol, B. (2019). Interactive Effects of Tree Mixing and Drought on a Primary Forest Pest. Frontiers in Forests and Global Change, 2, 1-12. doi: $\underline{10.3389 / f f g c .2019 .00077}$

Johnson, J. B., \& Omland, K. S. (2004). Model selection in ecology and evolution. Trends in Ecology \& Evolution, 19(2), 101-108. doi: 10.1016/i.tree.2003.10.013

Kambach, S., Kühn, I., Castagneyrol, B., \& Bruelheide, H. (2016). The Impact of Tree Diversity on Different Aspects of Insect Herbivory along a Global Temperature Gradient - A Meta-Analysis. Plos One, 11(11), e0165815. doi: 10.1371/journal.pone.0165815

Karban, R., \& Baldwin, I. T. (1997). Induced Responses to Herbivory. Chicago: Chicago University Press.

Karger, D. N., Conrad, O., Boehner, J., Kawohl, T., Kreft, H., Soria-Auza, R. W., ... Kessler, M. (2017). Data Descriptor: Climatologies at high resolution for the earth's land surface areas. Scientific Data, 4, 170122. doi: $10.1038 /$ sdata.2017.122

Kembel, S. W., Cowan, P. D., Helmus, M. R., Cornwell, W. K., Morlon, H., Ackerly, D. D., ... Webb, C. O. (2010). Picante: R tools for integrating phylogenies and ecology. Bioinformatics, 26(11), 1463-1464. doi: $10.1093 /$ bioinformatics/bta166

Klapwijk, M. J., Ayres, M. P., Battisti, A., \& Larsson, S. (2012). Assessing the impact of climate change on outbreak potential. In P. Barbosa, D. K. Letourneau, \& A. A. Agrawal (Eds.), Insect outbreak revisited (pp. 429-450). Wiley-Blackwell.

Koricheva, J., Larsson, S., Haukioja, E., \& Keinänen, M. (1998). Regulation of Woody Plant Secondary Metabolism by Resource Availability: Hypothesis Testing by Means of Meta-Analysis. Oikos, 83(2), 212226. doi: $10.2307 / 3546833$

Kostenko, O., Mulder, P. P. J., Courbois, M., \& Bezemer, T. M. (2017). Effects of plant diversity on the concentration of secondary plant metabolites and the density of arthropods on focal plants in the field. Journal of Ecology, 105(3), 647-660. doi: 10.1111/1365-2745.12700 
Kozlov, M. V., Lanta, V., Zverev, V., \& Zvereva, E. L. (2015). Global patterns in background losses of woody plant foliage to insects. Global Ecology and Biogeography, 24(10), 1126-1135. doi: 10.1111/geb.12347

Kuokkanen, K., Julkunen-Tiitto, R., Keinänen, M., Niemelä, P., \& Tahvanainen, J. (2001). The effect of elevated $\mathrm{CO} 2$ and temperature on the secondary chemistry of Betula pendula seedlings. Trees, 15(6), 378-384. doi: 10.1007/s004680100108

Kuznetsova, A., Brockhoff, P. B., \& Christensen, R. H. B. (2017). ImerTest Package: Tests in Linear Mixed Effects Models. Journal of Statistical Software, 82(13), 1-26. doi: 10.18637/jss.v082.i13

Lahtinen, M., Salminen, J.-P., Kapari, L., Lempa, K., Ossipov, V., Sinkkonen, J., ... Pihlaja, K. (2004). Defensive Effect of Surface Flavonoid Aglycones of Betula pubescens Leaves Against First Instar Epirrita autumnata Larvae. Journal of Chemical Ecology, 30(11), 2257-2268. doi: 10.1023/B:JOEC.0000048787.34388.dd

Lange, E. S., Kyryczenko-Roth, V., Johnson-Cicalese, J., Davenport, J., Vorsa, N., \& Rodriguez-Saona, C. (2019). Increased nutrient availability decreases insect resistance in cranberry. Agricultural and Forest Entomology, 21(3), 326-335. doi: 10.1111/afe.12335

Larsson, S., Wirén, A., Lundgren, L., \& Ericsson, T. (1986). Effects of Light and Nutrient Stress on Leaf Phenolic Chemistry in Salix dasyclados and Susceptibility to Galerucella lineola (Coleoptera). Oikos, 47(2), 205-210. doi: $\underline{10.2307 / 3566047}$

Letourneau, D. K., Armbrecht, I., Rivera, B. S., Lerma, J. M., Carmona, E. J., Daza, M. C., ... Trujillo, A. R. (2011). Does plant diversity benefit agroecosystems? A synthetic review. Ecological Applications, 21(1), 9-21. doi: $10.1890 / 09-2026.1$

Liang, J., Crowther, T. W., Picard, N., Wiser, S., Zhou, M., Alberti, G., ... Reich, P. B. (2016). Positive biodiversity-productivity relationship predominant in global forests. Science, 354(6309), aaf8957. doi: $\underline{10.1126 / \text { science.aaf8957 }}$

Lintunen, A., \& Kaitaniemi, P. (2010). Responses of crown architecture in Betula pendula to competition are dependent on the species of neighbouring trees. Trees, 24(3), 411-424. doi: 10.1007/s00468-010-0409-x

Loranger, H., Weisser, W. W., Ebeling, A., Eggers, T., De Luca, E., Loranger, J., ... Meyer, S. T. (2014). Invertebrate herbivory increases along an experimental gradient of grassland plant diversity. Oecologia, 174(1), 183-193. doi: 10.1007/s00442-013-2741-5

Loughnan, D., \& Williams, J. L. (2018). Climate and leaf traits, not latitude, explain variation in plantherbivore interactions across a species' range. Journal of Ecology, 107(2), 913-922. doi: 10.1111/1365$\underline{2745.13065}$

Magallón, S., Gómez-Acevedo, S., Sánchez-Reyes, L. L., \& Hernández-Hernández, T. (2015). A metacalibrated time-tree documents the early rise of flowering plant phylogenetic diversity. New Phytologist, 207(2), 437-453. doi: 10.1111/nph.13264

Merwin, A. C., Underwood, N., \& Inouye, B. D. (2017). Increased consumer density reduces the strength of neighborhood effects in a model system. Ecology, 98(11), 2904-2913. doi: $10.1002 / e c y .200$

Miller, E. T., Farine, D. R., \& Trisos, C. H. (2017). Phylogenetic community structure metrics and null models: a review with new methods and software. Ecography, 40(4), 461-477. doi: 10.1111/ecog.02070

Mole, S., Ross, J. A. M., \& Waterman, P. G. (1988). Light-induced variation in phenolic levels in foliage of rain-forest plants. I. Chemical Changes. Journal of Chemical Ecology, 14(1), 1-21. 
Moles, A. T., Bonser, S. P., Poore, A. G. B., Wallis, I. R., \& Foley, W. J. (2011). Assessing the evidence for latitudinal gradients in plant defence and herbivory. Functional Ecology, 25(2), 380-388. doi: 10.1111/j.1365-2435.2010.01814.x

Moreira, X., Abdala-Roberts, L., Parra-Tabla, V., \& Mooney, K. A. (2014). Positive Effects of Plant Genotypic and Species Diversity on Anti-Herbivore Defenses in a Tropical Tree Species. PLOS ONE, 9(8), e105438. doi: 10.1371/journal.pone.0105438

Moreira, X., Abdala-Roberts, L., Parra-Tabla, V., \& Mooney, K. A. (2015). Latitudinal variation in herbivory: influences of climatic drivers, herbivore identity and natural enemies. Oikos, 124(11), 14441452. doi: $10.1111 /$ oik.02040

Moreira, X., Castagneyrol, B., Abdala-Roberts, L., Teran, J. C. B.-M. y, Timmermans, B. G. H., Bruun, H. H., ... Tack, A. J. M. (2018). Latitudinal variation in plant chemical defences drives latitudinal patterns of leaf herbivory. Ecography, 41(7), 1124-1134. doi: 10.1111/ecog.03326

Moreira, X., Galman, A., Francisco, M., Castagneyrol, B., \& Abdala-Roberts, L. (2018). Host plant frequency and secondary metabolites are concurrently associated with insect herbivory in a dominant riparian tree. Biology Letters, 14(12), 20180281. doi: 10.1098/rsbl.2018.0281

Mraja, A., Unsicker, S. B., Reichelt, M., Gershenzon, J., \& Roscher, C. (2011). Plant Community Diversity Influences Allocation to Direct Chemical Defence in Plantago lanceolata. PLOS ONE, 6(12), e28055. doi: $\underline{10.1371 / \text { journal.pone.0028055 }}$

Muiruri, E. W., Barantal, S., lason, G. R., Salminen, J., Perez-Fernandez, E., \& Koricheva, J. (2019). Forest diversity effects on insect herbivores: do leaf traits matter? New Phytologist, 221(4), 2250-2260. doi: $\underline{10.1111 / n p h .15558}$

Muiruri, E. W., Milligan, H. T., Morath, S., \& Koricheva, J. (2015). Moose browsing alters tree diversity effects on birch growth and insect herbivory. Functional Ecology, 29(5), 724-735. doi: 10.1111/1365$\underline{2435.12407}$

Mundim, F. M., \& Pringle, E. G. (2018). Whole-Plant Metabolic Allocation Under Water Stress. Frontiers in Plant Science, 9, 852. doi: 10.3389/fpls.2018.00852

Nakagawa, S., \& Schielzeth, H. (2013). A general and simple method for obtaining R2 from generalized linear mixed-effects models. Methods in Ecology and Evolution, 4(2), 133-142. doi: 10.1111/i.2041210x.2012.00261.x

Ness, J. H., Rollinson, E. J., \& Whitney, K. D. (2011). Phylogenetic distance can predict susceptibility to attack by natural enemies. Oikos, 120(9), 1327-1334. doi: 10.1111/i.1600-0706.2011.19119.x

Paquette, A., Hector, A., Castagneyrol, B., Vanhellemont, M., Koricheva, J., Scherer-Lorenzen, M., \& Verheyen, K. (2018). A million and more trees for science. Nature Ecology \& Evolution, 2(5), 763-766. doi: $\underline{10.1038 / s 41559-018-0544-0}$

Pineau, X., David, G., Peter, Z., Sallé, A., Baude, M., Lieutier, F., \& Jactel, H. (2017). Effect of temperature on the reproductive success, developmental rate and brood characteristics of Ips sexdentatus (Boern.): Temperature effect on I. sexdentatus brood. Agricultural and Forest Entomology, 19(1), 23-33. doi: 10.1111/afe.12177

R Core Development Team. (2013). R: A language and environment for statistical computing. Retrieved from http://www.R-project.org/

Ratcliffe, S., Wirth, C., Jucker, T., van der Plas, F., Scherer-Lorenzen, M., Verheyen, K., ... Ohse, B. (2017). Biodiversity and ecosystem functioning relations in European forests depend on environmental context. Ecology Letters, 20(11), 1414-1426. doi: doi.org/10.1111/ele.12849 
Redding, D. W., Hartmann, K., Mimoto, A., Bokal, D., DeVos, M., \& Mooers, A. O. (2008). Evolutionarily distinctive species often capture more phylogenetic diversity than expected. Journal of Theoretical Biology, 251, 606-615. doi: 10.1016/j.jtbi.2007.12.006

Redding, D. W., \& Mooers, A. O. (2006). Incorporating evolutionary measure into conservation prioritization. Conservation Biology, 20(6), 1670-1678. doi: 10.1111/i.1523-1739.2006.00555.x

Riipi, M., Kause, A., Haukioja, E., Ossipov, V., Ossipova, S., \& Pihlaja, K. (2005). Variable responses of folivorous sawflies to leaf quality of mountain birch. Canadian Journal of Forest Research, 35(1), 189198. doi: $\underline{10.1139 / \times 04-166}$

Rodríguez-Castañeda, G. (2013). The world and its shades of green: a meta-analysis on trophic cascades across temperature and precipitation gradients. Global Ecology and Biogeography, 22(1), 118-130. doi: 10.1111/j.1466-8238.2012.00795.x

Root, R. B. (1973). Organization of a Plant-Arthropod Association in Simple and Diverse Habitats: The Fauna of Collards (Brassica Oleracea). Ecological Monographs, 43(1), 95-124. doi: 10.2307/1942161

Rosado-Sánchez, S., Parra-Tabla, V., Betancur-Ancona, D., Moreira, X., \& Abdala-Roberts, L. (2017). Tree species diversity alters plant defense investment in an experimental forest plantation in southern Mexico. Biotropica, 50(2), 246-253. doi: 10.1111/btp.12527

Rosado-Sánchez, S., Parra-Tabla, V., Betancur-Ancona, D., Moreira, X., \& Abdala-Roberts, L. (2018). Effects of tree species diversity on insect herbivory and leaf defences in Cordia dodecandra. Ecological Entomology, 43(6), 703-711. doi: 10.1111/een.12648

Roslin, T., Hardwick, B., Novotny, V., Petry, W. K., Andrew, N. R., Asmus, A., ... Slade, E. M. (2017). Higher predation risk for insect prey at low latitudes and elevations. Science, 356(6339), 742-744. doi: $\underline{10.1126 / \text { science.aaj1631 }}$

Russell, E. P. (1989). Enemies Hypothesis: A Review of the Effect of Vegetational Diversity on Predatory Insects and Parasitoids. Environmental Entomology, 18(4), 590-599. doi: 10.1093/ee/18.4.590

Schemske, D. W., Mittelbach, G. G., Cornell, H. V., Sobel, J. M., \& Roy, K. (2009). Is There a Latitudinal Gradient in the Importance of Biotic Interactions? Annual Review of Ecology Evolution and Systematics, 40, 245-269. doi: 10.1146/annurev.ecolsys.39.110707.173430

Schielzeth, H. (2010). Simple means to improve the interpretability of regression coefficients: Interpretation of regression coefficients. Methods in Ecology and Evolution, 1(2), 103-113. doi: 10.1111/j.2041-210X.2010.00012.x

Schuldt, A., Assmann, T., Bruelheide, H., Durka, W., Eichenberg, D., Härdtle, W., ... Purschke, O. (2014). Functional and phylogenetic diversity of woody plants drive herbivory in a highly diverse forest. New Phytologist, 202(3), 864-873. doi: 10.1111/nph.12695

Schuldt, A., Baruffol, M., Böhnke, M., Bruelheide, H., Härdtle, W., Lang, A. C., ... Assmann, T. (2010). Tree diversity promotes insect herbivory in subtropical forests of south-east China. Journal of Ecology, 98(4), 917-926. doi: 10.1111/i.1365-2745.2010.01659.x

Schuldt, A., Bruelheide, H., Härdtle, W., Assmann, T., Li, Y., Ma, K., ... Zhang, J. (2015). Early positive effects of tree species richness on herbivory in a large-scale forest biodiversity experiment influence tree growth. Journal of Ecology, 103(3), 563-571. doi: 10.1111/1365-2745.12396

Setiawan, N. N., Vanhellemont, M., Baeten, L., Dillen, M., \& Verheyen, K. (2014). The effects of local neighbourhood diversity on pest and disease damage of trees in a young experimental forest. Forest Ecology and Management, 334, 1-9. doi: 10.1016/i.foreco.2014.08.032

Siemann, E., Tilman, D., Haarstad, J., \& Ritchie, M. (1998). Experimental Tests of the Dependence of Arthropod Diversity on Plant Diversity. The American Naturalist, 152(5), 738-750. 
Srivastava, D. S., Cadotte, M. W., MacDonald, A. A. M., Marushia, R. G., \& Mirotchnick, N. (2012). Phylogenetic diversity and the functioning of ecosystems. Ecology Letters, 15(7), 637-648. doi: 10.1111/j.1461-0248.2012.01795.x

Stone, A. C., Gehring, C. A., \& Whitham, T. G. (2010). Drought negatively affects communities on a foundation tree: growth rings predict diversity. Oecologia, 164(3), 751-761. doi: 10.1007/s00442-0101684-3

Vehvilainen, H., Koricheva, J., \& Ruohomaki, K. (2007). Tree species diversity influences herbivore abundance and damage: meta-analysis of long-term forest experiments. Oecologia, 152(2), 287-298. doi: $\underline{10.1007 / s 00442-007-0673-7}$

Verheyen, K., Vanhellemont, M., Auge, H., Baeten, L., Baraloto, C., Barsoum, N., ... Scherer-Lorenzen, M. (2016). Contributions of a global network of tree diversity experiments to sustainable forest plantations. Ambio, 45(1), 29-41. doi: 10.1007/s13280-015-0685-1

Veteli, T. O., Kuokkanen, K., Julkunen-Tiitto, R., Roininen, H., \& Tahvanainen, J. (2002). Effects of elevated $\mathrm{CO} 2$ and temperature on plant growth and herbivore defensive chemistry. Global Change Biology, 8(12), 1240-1252. doi: 10.1046/j.1365-2486.2002.00553.x

Visakorpi, K., Riutta, T., Martínez-Bauer, A. E., Salminen, J., \& Gripenberg, S. (2019). Insect community structure covaries with host plant chemistry but is not affected by prior herbivory. Ecology, 100(8), e02739. doi: $10.1002 /$ ecy.2739

Walter, J., Hein, R., Auge, H., Beierkuhnlein, C., Löffler, S., Reifenrath, K., ... Jentsch, A. (2012). How do extreme drought and plant community composition affect host plant metabolites and herbivore performance? Arthropod-Plant Interactions, 6(1), 15-25. doi: 10.1007/s11829-011-9157-0

Wang, X.-F., Liu, J.-F., Gao, W.-Q., Deng, Y.-P., Ni, Y.-Y., Xiao, Y.-H., ... Jiang, Z.-P. (2016). Defense pattern of Chinese cork oak across latitudinal gradients: influences of ontogeny, herbivory, climate and soil nutrients. Scientific Reports, 6, 27269. doi: 10.1038/srep27269

Wein, A., Bauhus, J., Bilodeau-Gauthier, S., Scherer-Lorenzen, M., Nock, C., \& Staab, M. (2016). Tree Species Richness Promotes Invertebrate Herbivory on Congeneric Native and Exotic Tree Saplings in a Young Diversity Experiment. PLOS ONE, 11(12), e0168751. doi: 10.1371/journal.pone.0168751

Yguel, B., Bailey, R., Tosh, N. D., Vialatte, A., Vasseur, C., Vitrac, X., ... Prinzing, A. (2011). Phytophagy on phylogenetically isolated trees: why hosts should escape their relatives. Ecology Letters, 14(11), 1117-1124. doi: 10.1111/j.1461-0248.2011.01680.x

Zhang, Q.-H., \& Schlyter, F. (2004). Olfactory recognition and behavioural avoidance of angiosperm nonhost volatiles by conifer-inhabiting bark beetles. Agricultural and Forest Entomology, 6(1), 1-20. doi: 10.1111/j.1461-9555.2004.00202.x

Zhang, Y., Chen, H. Y. H., \& Reich, P. B. (2012). Forest productivity increases with evenness, species richness and trait variation: a global meta-analysis: Diversity and productivity relationships. Journal of Ecology, 100(3), 742-749. doi: 10.1111/j.1365-2745.2011.01944.x

Zúbrik, M., Kunca, A., \& Csóka, G. (2013). Insects and diseases damaging trees and shrubs of Europe (N.A.P. Editions). 


\section{Tables}

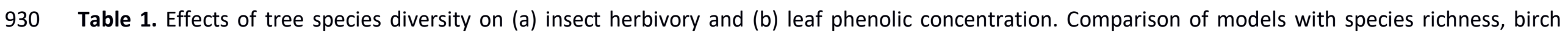
evolutionary distinctiveness (ED) or both diversity metrics as predictors. Bold predictors have a significant effect. AICc*: best (lowest) AICc.

\begin{tabular}{|c|c|c|c|c|c|c|c|c|c|}
\hline \multirow{2}{*}{ Predictors } & \multirow{2}{*}{$\begin{array}{l}\text { Standardized } \\
\text { estimate } \pm \text { sd }\end{array}$} & \multirow{2}{*}{ df } & \multirow{2}{*}{$\begin{array}{c}\mathrm{t}- \\
\text { value }\end{array}$} & \multirow{2}{*}{ P-value } & \multirow{2}{*}{$R_{m}^{2}\left(R_{c}^{2}\right)$} & \multirow{2}{*}{$\mathrm{AlCc}$} & \multicolumn{3}{|c|}{ Random intercept effects (Variance $\pm \mathrm{sd}$ ) } \\
\hline & & & & & & & Site & Block:Site & Plot:Block:Site \\
\hline \multicolumn{10}{|l|}{ a) Herbivory } \\
\hline w/ Sp. richness & & & & & $0.00(0.57)$ & $2322.47^{*}$ & $3.10 \pm 1.76$ & $0.25 \pm 0.50$ & $0.46 \pm 0.68$ \\
\hline Intercept & $3.81 \pm 0.53$ & 11.28 & 7.24 & $<0.001$ & & & & & \\
\hline Species richness & $-0.03 \pm 0.09$ & 143.74 & -0.34 & 0.737 & & & & & \\
\hline w/ Birch ED & & & & & $0.00(0.57)$ & $2322.57^{*}$ & $3.10 \pm 1.76$ & $0.25 \pm 0.50$ & $0.46 \pm 0.68$ \\
\hline Intercept & $3.81 \pm 0.53$ & 11.28 & 7.25 & $<0.001$ & & & & & \\
\hline Birch ED & $0.01 \pm 0.09$ & 122.90 & 0.11 & 0.916 & & & & & \\
\hline \multicolumn{2}{|c|}{ w/ Sp. Richness and Birch ED } & & & & $0.00(0.57)$ & 2328.52 & $3.07 \pm 1.75$ & $0.25 \pm 0.50$ & $0.45 \pm 0.67$ \\
\hline Intercept & $3.75 \pm 0.53$ & 11.42 & 7.12 & $<0.001$ & & & & & \\
\hline Species richness & $0.01 \pm 0.10$ & 140.37 & 0.11 & 0.916 & & & & & \\
\hline Birch ED & $0.16 \pm 0.13$ & 128.18 & 1.20 & 0.231 & & & & & \\
\hline \multicolumn{10}{|c|}{ Sp. richness $\times$ Birch } \\
\hline ED & $0.27 \pm 0.17$ & 135.56 & 1.56 & 0.121 & & & & & \\
\hline \multicolumn{10}{|l|}{ b) Phenolics } \\
\hline w/ Sp. richness & & & & & $0.00(0.65)$ & 5819.74 & $5930 \pm 77$ & $0 \pm 0$ & $1663 \pm 41$ \\
\hline Intercept & $332.29 \pm 23.67$ & 10.09 & 14.04 & $<0.001$ & & & & & \\
\hline Species richness & $4.35 \pm 4.67$ & 146.67 & 0.93 & 0.353 & & & & & \\
\hline w/ Birch ED & & & & & $0.02(0.65)$ & 5810.79 & $5953 \pm 77$ & $0 \pm 0$ & $1446 \pm 38$ \\
\hline Intercept & $331.80 \pm 23.68$ & 10.09 & 14.01 & & & & & & \\
\hline Birch ED & $-15.05 \pm 4.71$ & 126.40 & -3.19 & 0.002 & & & & & \\
\hline \multicolumn{2}{|c|}{ w/ Sp. Richness and Birch ED } & & & & $0.03(0.65)$ & $5798.61^{*}$ & $5997 \pm 77$ & $0 \pm 0$ & $1375 \pm 37$ \\
\hline Intercept & $332.00 \pm 23.87$ & 10.26 & 13.91 & $<0.001$ & & & & & \\
\hline Species richness & $10.74 \pm 4.90$ & 141.50 & 2.19 & 0.030 & & & & & \\
\hline Birch ED & $-19.33 \pm 6.87$ & 147.95 & -2.82 & $<0.006$ & & & & & \\
\hline \multicolumn{10}{|c|}{ Sp. richness $x$ Birch } \\
\hline ED & $-0.43 \pm 8.98$ & 156.27 & -0.05 & 0.962 & & & & & \\
\hline
\end{tabular}


Table 2. Effects of tree diversity, temperature and rainfall on (a) insect herbivory and (b) leaf phenolic concentration. Predictors that were excluded from the final model during simplification are not shown. Bold predictors have a significant effect.

\begin{tabular}{|c|c|c|c|c|c|}
\hline Predictors & $\begin{array}{l}\text { Standardized } \\
\text { estimate } \pm \text { sd }\end{array}$ & df & t-value & P-value & $R_{m}^{2}\left(R_{c}^{2}\right)$ \\
\hline \multicolumn{6}{|l|}{ a) Herbivory } \\
\hline w/ Sp. richness & & & & & $0.22(0.59)$ \\
\hline Intercept & $3.81 \pm 0.43$ & 10.35 & 8.93 & $<0.001$ & \\
\hline Species richness & $-0.05 \pm 0.09$ & 142.59 & -0.551 & 0.582 & \\
\hline Temperature & $1.21 \pm 0.46$ & 10.26 & 2.64 & 0.024 & \\
\hline \multirow[t]{2}{*}{ Sp. richness x Temperature } & $0.19 \pm 0.09$ & 135.27 & 2.14 & 0.034 & \\
\hline & \multicolumn{4}{|l|}{ Variance $\pm s d$} & \\
\hline Site & $1.95 \pm 1.40$ & & & & \\
\hline Block:Site & $0.25 \pm 0.50$ & & & & \\
\hline Plot:(Block:Site) & $0.41 \pm 0.64$ & & & & \\
\hline \multicolumn{5}{|l|}{ w/ Birch ED } & $0.21(0.59)$ \\
\hline Intercept & $3.82 \pm 0.42$ & 10.34 & 9.05 & $<0.001$ & \\
\hline Temperature & $1.21 \pm 0.45$ & 10.24 & 2.68 & 0.023 & \\
\hline \multicolumn{6}{|c|}{ Variance $\pm s d$} \\
\hline Site & \multicolumn{5}{|l|}{$1.91 \pm 1.38$} \\
\hline Block:Site & \multicolumn{5}{|l|}{$0.25 \pm 0.50$} \\
\hline Plot:(Block:Site) & \multicolumn{5}{|l|}{$0.45 \pm 0.67$} \\
\hline \multicolumn{5}{|c|}{ b) Phenolics w/ Sp. Richness and Birch ED } & $0.46(0.67)$ \\
\hline Intercept & $327.30 \pm 13.30$ & 6.89 & 24.62 & $<0.001$ & \\
\hline Species richness & $11.47 \pm 4.39$ & 148.33 & 2.61 & 0.010 & \\
\hline Birch ED & $-13.37 \pm 5.16$ & 140.89 & -2.59 & 0.011 & \\
\hline Temperature & $53.06 \pm 14.32$ & 6.82 & 3.71 & 0.008 & \\
\hline Rainfall & $-31.14 \pm 13.33$ & 6.83 & -2.34 & 0.053 & \\
\hline Birch ED x Temperature & $-8.84 \pm 4.89$ & 124.77 & -1.81 & 0.073 & \\
\hline Birch ED x Rainfall & $-5.15 \pm 4.75$ & 131.52 & -1.09 & 0.280 & \\
\hline Temp. x Rainfall & $29.79 \pm 12.72$ & 6.72 & 2.34 & 0.053 & \\
\hline \multirow[t]{2}{*}{ Birch ED x Temp. x Rainfall } & $-13.22 \pm 4.15$ & 121.02 & -3.19 & 0.002 & \\
\hline & \multicolumn{4}{|l|}{ Variance $\pm \mathrm{sd}$} & \\
\hline Site & \multicolumn{5}{|l|}{$1586.60 \pm 39.82$} \\
\hline Block:Site & \multicolumn{5}{|l|}{$0.00 \pm 0.00$} \\
\hline Plot:(Block:Site) & \multicolumn{5}{|l|}{$993.60 \pm 31.52$} \\
\hline
\end{tabular}


Table 3. Effects of leaf phenolic concentration on insect herbivory as a covariate of tree diversity, temperature and rainfall. Predictors that were excluded from the final model during simplification are not shown. Bold predictors have a significant effect.

\begin{tabular}{|c|c|c|c|c|c|}
\hline Predictors & $\begin{array}{l}\text { Standardized } \\
\text { estimate } \pm \text { sd }\end{array}$ & $\mathrm{df}$ & t-value & P-value & $\mathrm{R}_{\mathrm{m}}^{2}\left(\mathrm{R}_{\mathrm{c}}^{2}\right)$ \\
\hline \multicolumn{5}{|l|}{ Herbivory w/ Sp. Richness } & $0.24(0.58)$ \\
\hline Intercept & $3.96 \pm 0.43$ & 9.30 & 9.20 & $<0.001$ & \\
\hline Temperature & $1.41 \pm 0.45$ & 9.57 & 3.15 & 0.011 & \\
\hline \multirow[t]{2}{*}{ Phenolics } & $-0.29 \pm 0.12$ & 466.99 & -2.39 & 0.017 & \\
\hline & Variance $\pm \mathrm{sd}$ & & & & \\
\hline Site & $1.77 \pm 1.33$ & & & & \\
\hline Block:Site & $0.30 \pm 0.55$ & & & & \\
\hline Plot:(Block:Site) & $0.42 \pm 0.65$ & & & & \\
\hline \multicolumn{5}{|l|}{ Herbivory w/ Birch ED } & $0.25(0.59)$ \\
\hline Intercept & $3.99 \pm 0.44$ & 9.29 & 9.11 & $<0.001$ & \\
\hline Birch ED & $0.02 \pm 0.10$ & 111.88 & 0.22 & 0.826 & \\
\hline Temperature & $1.41 \pm 0.46$ & 9.54 & 3.11 & 0.012 & \\
\hline Phenolics & $-0.25 \pm 0.12$ & 476.63 & -2.04 & 0.042 & \\
\hline \multirow[t]{2}{*}{ Birch ED x Phenolics } & $0.23 \pm 0.10$ & 285.52 & 2.42 & 0.016 & \\
\hline & Variance \pm sd & & & & \\
\hline Site & $1.84 \pm 1.36$ & & & & \\
\hline Block:Site & $0.31 \pm 0.55$ & & & & \\
\hline Plot:(Block:Site) & $0.35 \pm 0.59$ & & & & \\
\hline
\end{tabular}

